\title{
LA ENTIDAD MUNICIPAL METROPOLITANA DE BARCELONA
}

\author{
711.414 (46, Barcelona)
}

por

\section{Gumersindo Guerra-Librero y Arroyo}

SUMARIO: I. INTRODUCCION.-II. CONCEPTO: 1. MUNICIPIOS QUE LA INTEGRAN. 2. IMPORTANCIA DE SU CREACIÓN. 3. FunCIONES. 4. NuEVO ENTE TERRITORIAL.-III. RAZON DE SER O CAUSA DE LA ENTIDAD MUNICIPAL METROPOLITANA DE BARCELONA: 1. QUÉ SE HARA del Plan Comarcal. 2. Preocupación por el Reglamento de la Entidad Municipal Metropolitana de Barcelona.-IV. ORGaNOS RECTORES: 1. El Consejo Metropolitano: A) Concepto. B). Representantes. C) Presidente. D) Posición del Alcalde de Barcelona dentro de la Entidad Municipal Metropolitana de Barcelona. E) Competencias del Consejo y de su Presidente. 2. La Comisión AdministraTIVA: A) Concepto. B) Composición. C) Justificación. D) Facultades. E) Sesiones del Consejo y de la Comisión Administrativa y adopción de acuerdos. 3. La Gerencia Metropolitana: A) Concepto. B) El Gerente. C) Atribuciones del Gerente. D) Direcciones de servicio y funcionarios.-V. PLANEAMIENTO URBANISTICO Y SU EJECUCION: 1. Contenido del Planeamiento metropolitano: A) Planes parciales. B) Catálogo de edificios, conjuntos, etc. C) Normas complementarias del Plan General. 2. COORDINACIÓN DE ACTUACIONES URBAnfsticas en la zona metropolitana. 3. Programa de actuaciones, OBRAS Y SERVICIOS. 4. COMPETENCIA URBANISTICA DE LOS AYUNTAMIENTOS DE LA ZONA METROPOLITANA. 5. OTORGAMIENTO DE LICENCIAS URBANISTICAS. 6. COMPETENCIAS DE LA «CORPORACIÓN» EN LA ACTUACIÓN URBANFSTICA DE LOS MUNICIPIOS.-VI. SERVICIOS PUBLICOS DE INTERES METROPOLITANO: 1. TRANSFORMACION DE SERVICIOS MUNICIPALES EN SERVICIOS DE INTERÉS METROPOLITANO. 2. LA Entidad Municipal Metropolitana de Barcelona más eficiente en CUANTO A SERVICIOS. 3. ¿QUIÉN PAGARÁ LOS SERVICIOS? 4. EL SERVICIO 
DE TRANSPORTES URBanOS. 5. FaCUlTades dE LA "CORPORACIÓN» EN RElaCIÓN A DICHOS SERvicios: A) Asistencia técnica de la "Corporación» a los Municipios. B) Trámite para la asunción del establecimiento $y$ prestación de un servicio concreto.-VII. REGIMEN FINANCIERO DE LA «CORPORACION»: 1. INGRESOS. 2. EXTENSIÓN DEL RÉGIMEN FISCAL DE BARCELONA.-VIII. DIPUTACION PROVINCIAL Y PLAN PROVINCIAL DE URBANISMO.-IX. ORGANO DESCONCENTRADO: 1. Competencias. 2. CRfticas.-X. CRITICAS SOBRE LA ENTIDAD MUNICIPAL METROPOLITANA DE BARCELONA: 1. INSUFICIENTE EXTENSIÓN TERRITORIAL. 2. F

3. OTRAS CRfTICAS.-XI. CONCLUSION.

\section{INTRODUCCION}

Sobre la estructura de las Areas Metropolitanas no es raro que se busquen nuevas soluciones. Así se ha hecho en el curso de los últimos años, y ello explica la aparición de complejas reordenaciones (en Toronto, París, Londres) o de reordenaciones parciales (Varsovia).

Es indudable el carácter de gran complejidad de los problemas y la necesidad de profundos análisis y de definiciones generales que provocan (1).

Es hoy preocupación general la necesidad de una estructuración orgánica y funcional de las Areas Metropolitanas encaminada a renovar las tradicionales estructuras locales, esto sin desconocer las anteriores experiencias.

En Barcelona venían funcionando estructuras urbanísticas supramunicipales, creadas a raíz de la Ley de 3 de diciembre de 1953 y perfeccionadas posteriormente en la Ley especial de Barcelona, que han constituido instrumentos valiosos en orden a la coordinación de la actividad urbanística y de la gestión de las obras y servicios municipales comunes. Sobre este punto de partida se aspiraba a configurar una nueva articulación institucional en función de las últimas exigencias derivadas del fenómeno metropolitano y de su planteamiento.

Se hacía preciso configurar un organismo al que se encomendase esencialmente la misión de orientar e impulsar el desarrollo del planeamiento, organismo que debería velar para que los programas de realización e inversiones que los Departamentos ministeriales y

(1) H. Puget, aLes nouvelles structures de la région parisiennes, Revue Internationale des Sciènces Administratives, núm. 1, 1965. 
sus organismos autónomos se propongan realizar se adecuen al planeamiento metropolitano, y al propio tiempo procurar que la prestación de los servicios metropolitanos a cargo de las Entidades locales se realice con criterios de unidad y coordinación. Con esta finalidad ha sido creada la Entidad Municipal Metropolitana de Barcelona (EMMB).

\section{CONCEPTO}

Según el Decreto-ley 5/1974, de 24 de agosto, la EMMB «es un órgano específico para el impulso, coordinación, gestión, vigilancia y ejecución del planeamiento urbanístico y de la prestación de aquellos servicios de interés relevante para el conjunto de la zona metropolitana» (a. 1.1).

La EMMB, denominada Corporación Metropolitana de Barcelona, y en lo sucesivo "Corporación», tiene el carácter de Entidad local con plena capacidad jurídica en los términos previstos en el artículo $60^{\circ}$ de la Ley de Régimen local, y le serán de aplicación dicha Ley y sus disposiciones complementarias en cuanto no resulten modificadas por el Decreto-ley anteriormente citado de 1974 y disposiciones que lo desarrollan (2).

Masó ha dicho que "si lo analizamos con detalle, veremos que por primera vez vamos a una unión entre entes locales de la comarca» (3).

UdiNa MARTORELl ve en este Decreto-ley «una versión municipalista de la estructura metropolitana, por el hecho fundamental de que la Comisión de Urbanismo se ha convertido en una Entidad municipal autóctona». Su opinión es que se ha restituido a los Municipios una función que realizaba un órgano municipal, y lógicamente se tenía que crear la EMMB antes de entrar en la discusión del nuevo Estatuto de Régimen local, por la sencilla razón de avanzarse al trámite que comporta la discusión, aprobación y desarrollo del citado Estatuto (4).

El hecho de que existan representantes de la Diputación Provincial parece que el término "municipal» se ha confundido con

(2) Vid. artículos $10^{\circ}$ y $20^{\circ}$ del Decreto $3.276 / 1974$, de 28 de noviembre, que desarrolla el Decreto-ley 5/1974.

(3) Vid. Discursos pronunciados por Maso el 30 de septiembre y el 26 de noviembre de 1974.

(4) Vid. El Correo Catalán, 11 de octubre de 1974. 
«local», ya que esta denominación abarcaría a los representantes "provinciales» y a los «locales» propiamente dicho.

\section{MUNicipios QUe LA INTEGRAN}

En la EMMB se integran veintiocho Municipios que pretenden sincretizar todo cuanto a la ordenación del territorio se refiere en el ámbito a que abarcan sus términos. Estos Municipios son los siguientes: Barcelona, Badalona, Castelldefels, Cornellá, Esplugas, Gavá, Hospitalet de Llobregat, Les Botigues de Sitges, Molins de Rey, Moncada y Reixach, Mongat, Pallejá, Papiol, Prat de Llobregat, Ripollet, San Adrián de Besós, San Baudilio de Llobregat; San Cugat del Vallés, San Clemente de Llobregat, San Feliú de Llobregat, San Juan Despí, San Justo Desvern, San Vicente dels Horts, Santa Coloma de Cervelló, Santa Coloma de Gramanet, Sardañola, Tiana y Viladecans.

El Gobierno, por Decreto a propuesta del Ministerio de la Gobernación, oído el Ministerio de la Vivienda y previa audiencia de los Ayuntamientos interesados, de la Diputación Provincial y del Consejo Metropolitano, podrá modificar el ámbito territorial de la Entidad e incluir en ella otras comarcas o Municipios colindantes cuando las circunstancias urbanísticas, sociológicas o de servicios lo aconsejen. La iniciación del expediente podrá acordarse de ofi cio, a instancia del Consejo Metropolitano o de los Municipios interesados en la alteración del ámbito territorial.

\section{IMPORTANCIA DE SU CREACIÓN}

La creación de la EMMB es el acto político más importante de Barcelona desde que, en 1953, se promulgara la Ley por la que se establecían las normas reguladoras del urbanismo barcelonés, aventajando a dicha Ley en el detalle fundamental de que en la nueva Entidad la descentralización administrativa le atribuye la mayoría de las competencias que hasta ahora venía detentando el Ministerio de la Vivienda. Es, al decir de Masó, uno de los hitos más importantes en la historia de la Administración local de España. 


\section{FunCIONES}

En cuanto a las funciones de la nueva Entidad, Masó afirmó que «la primera función de esta nueva etapa será la coordinación del territorio y de los servicios de la población de Barcelona y de las poblaciones afectadas por el nuevo Decreto-ley, instrumento válido para esta coordinación, cara al futuro, no sólo de Barcelona, en el sentido local, sino también para todos los Municipios que la rodean" (5).

Para Roca Junyent, las funciones de la nueva Entidad no son idénticas ni superiores a las de la Comisión de Urbanismo, porque mientras esta Comisión podía aprobar definitivamente los planes y proyectos que se dieran en desarrollo y sin modificación del Plan Comarcal, a la EMMB esto de aprobar definitivamente le está vedado, y el "poder" viene de "aprobar», no de "dibujar» (6).

Para MAS ConTr, la EMMB debiera haber tenido como objetivo fundamentalmente la planificación de lo que se entiende por Area Metropolitana. Y aclara: "se puede correr el riesgo de que dentro de veinte años el desorden que hoy impera en el territorio de los veintiocho Municipios de la EMMB se extienda a los ciento veintisiete del Area, con la grave responsabilidad de que ahora es más fácil preverlo de lo que lo fue entonces» (7).

Según BRogGi TRfAs, la EMMB no sólo suplanta las funciones que hasta ahora tenía la llamada Comisión de Urbanismo y Servicios Comunes, sino que al mismo tiempo no dispone de las atribuciones planificadoras con que esta última contaba (8).

\section{NUEVO ENTE TERRITORIAL}

Es indudable que con la creación de la EMMB ha nacido un nuevo ente territorial, pues en su área geográfica queda superado el concepto de ciudades o Municipios independientes entre sí, aunque bien sabido es que la metrópoli es la encrucijada de las relaciones

(5) Vid. Nuevo Diario, Barcelona, 1 septiembre 1974: «Enrique Masó habla de la Entidad Municipal Metropolitana de Barcelona».

(6) Vid. El Correo Catalán, Barcelona, 14 septiembre.

(7) Vid. Diario de Cataluña, Barcelona, 18 septiembre.

(8) A. Broggr Trfas, «Temas de economía regional. La nueva Entidad Metropolitana», La Vanguardia Española, Barcelona, 30 octubre. 
intergubernamentales. Se ha hecho realidad el concepto de Area Metropolitana con planificación y servicios comunes, a la vez que con fuentes financieras compartibles (9).

La formación de grandes unidades administrativas y gubernamentales no garantiza el desarrollo planificado de la metrópoli. Estas unidades deben disponer de poderes y de medios propios, aunque algunas de estas exigencias no se adquieran siempre al reestructurarse las ciudades territoriales (10).

En la zona sometida a esta Entidad habita aproximadamente el 90 por 100 de la población afincada en la Provincia, lo que equivale a unos 2.869.000 habitantes.

\section{RAZON DE SER O CAUSA DE LA EMMB}

Para PI y SuÑER, esta Entidad se ha creado para dejar en suspenso el Plan Comarcal, que "gustó mucho a distintos elementos extremistas, porque el ataque afectaba a la propiedad privada y a los sectores urbanísticos, pues ponía un freno a la superpoblación de Barcelona; no se podía hablar demasiado claro y por esta causa ahora ha podido parecer que la creación de la nueva Entidad municipal nada tiene que ver con el Plan, pero en mi punto de vista parece indiscutible, máxime cuando el Decreto-ley se ha dictado con una precipitación desacostumbrada y en pleno mes de agosto, cuando los proyectos grandes o pequeños descansan» (11).

El Conde AlBa DE LISTE también abundaba en esta opinión, afirmando que el Decreto-ley obedece a la necesidad de poner punto final a la revisión del Plan Comarcal.

Roca JUNYENT no alcanza a comprender "por qué para derribar la revisión del Plan Comarcal se tenía que acudir a una "revisión" total de la estructura administrativa de Barcelona en términos tales que encorsetan su desarrollo y niegan el reconocimiento de sus peculiaridades específicas como centro incuestionable de Cataluña» (12).

(9) REXACH, aBarcelona, una experiencia piloto: la Entidad Municipal Metropolitana», La Actualidad Española.

(10) Vid. Problemas de las Areas Metropolitanas, pág. 149.

(11) Vid. La Vanguardia Española, Barcelona, 5 septiembre 1974.

(12) R. Posadas, aLa Entidad Municipal Metropolitanas; en El Correo Catalán, 14 septiembre. 
Otros tratan de buscar una razón política en el nacimiento de la Entidad. Así, Miro I ARDEvol escribe:

«Nada parece justificar técnicamente la desaparición del Area Metropolitana y su sustitución por la Entidad. Entonces, ¿cuáles son las causas de tal proceder? A mi entender, la respuesta es sólo una: la razón es esencialmente política y tiene su causa primera en la desfavorable actitud que manifiesta la Administración central hacia la formación en Cataluña de unidades territoriales amplias, descentralizadas, con medios suficientes para hacer frente a los problemas de nuestro complejo tiempo. A esta causa inicial se le añaden otras de menor calibre, como pueden ser el interés de la Organización Sindical en intervenir en algo tan rentable como es la "política del suelo", o las pequeñas pugnas entre los designados regentes locales. La resultante de todo ello es una respuesta que llega con diez años de retraso, y que por ello resulta totalmente inadecuada a nuestras necesidades.

Una vez más la política invalida a la técnica: entonces, ¿por qué seguimos preocupándonos de los aspectos técnicos de nuestros problemas?» (13).

LLISET BorRell (14) halla la causa de esta Entidad «en la necesidad de ordenación racional de un territorio demográficamente congestionado, incidido por un desusado dinamismo social».

Alfredo ReXach escribe en La Actualidad Española: "Si se quiere sintetizar la finalidad fundamental de la nueva Entidad podríamos limitarnos a señalar que a través de ella se planificará urbanísticamente ese territorio" (15).

La Entidad se crea como una consecuencia de la expansión de Barcelona. Se trata de un ensayo a nivel provincial, planteado como experiencia piloto para resolver una serie de problemas que se generan en el entorno de las grandes urbes, como fruto de verterse las mismas sobre zonas de influencia muy calificadas.

El tema ha planteado múltiples interrogantes. Entre ellas una supuesta polémica entre el Municipio y la Diputación barcelonesa por hacerse con el control de lo que se llamó Area Metropolitana

(13) Josep Miro I ARdevol, «¿Qué fue del Area Metropolitana de Barcelona? Razones y sin razones de una mini-áreas, El Correo Catalán, 16 septiembre 1974.

(14) Francisco Lliset Borrell, "Caracteres de la E. M. M.», La Vanguardia Española, Barcelona, 5 septiembre 1974.

(15) Alfredo REXACH, «Barcelona, una experiencia piloto: la E. M. M.», La Actualidad Española. 
de Barcelona. La solución que parece dar la Entidad a estas cuestiones la califica Jordi CAPDEvilla de salomónica. De la superficie abarcada por el Area, la comarca de Barcelona pasaría a ser controlada por el Alcalde de la ciudad, mientras que el resto se deja a la planificación y gobierno provincial. Pero el dar esto por seguro en las actuales condiciones parece todavía prematuro (16).

SAMARANCH subrayó que "la Corporación quiere ocupar el sitio que le corresponde en el gobierno político y social de la Provincia, pero $-\mathrm{y}$ aquí debió preferir sacarle hierro a las notorias diferencias entre Diputación y Ayuntamiento en lo concerniente a la gran Barcelona- las cosas de Barcelona - prosiguió- deben resolverse en Barcelona; deseamos colaborar con todos los Municipios y especialmente con el de Barcelona, que es el más afectado" (17).

Para Miró I ARDEvol, «la creación de la EMMB equivale a la desaparición de la Comisión Gestora del Area Metropolitana y al traspaso de sus funciones a la Diputación Provincial.

En definitiva, los hechos concretos son dos: primero, la EMMB es simplemente la comarca ya existente con nombre cambiado, con una cierta ampliación de los recursos y funciones que actualmente posee la Comisión de Urbanismo de Barcelona y otros Municipios. Segundo, la liquidación definitiva del Area Metropolitana y el predominio, en este sentido, de la división provincial y las funciones de la Diputación" (18).

Refiriéndose a la presión ejercida por los que impugnaron el Plan Comarcal, ENTRENA Cuesta opina así: "Lo cierto es que, en definitiva, esto puede ocasionar una demora en la resolución de las mociones presentadas, puesto que será otro organismo, y por tanto otras personas, quienes ahora se pronuncien sobre el asunto. Por otra parte, hace ya tiempo, incluso antes de que se sometiera a información pública la revisión del Plan Comarcal, que se había señalado el carácter prioritario del problema del Area Metropolitana de Barcelona para el actual Gobierno» (19).

(16) Vid. Diario de Barcelona, 25 agosto 1974.

(17) Vid. Nuevo Diario, Barcelona, 1 septiembre 1974.

(18) Vid. El Correo Catalán, 16 septiembre 1974.

(19) Vid. El Correo Catalán, 22 septiembre 1974. 


\section{Qué se hara del Plan Comarcal}

Con respecto al futuro del Plan Comarcal hay mucho escepticismo en los medios técnicos. En la mente de muchos está la pregunta, ¿cuál va a ser el destino del Plan Comarcal tras la creación de la Entidad?

Rafael PRADAs ha escrito: «Se dice que hay muchas presiones de determinados grupos inmobiliarios-financieros para que tras el período de audiencia a las Corporaciones se levante la suspensión de licencias y, por otra parte, comienzan a darse algunos casos de "actuación" - para entendernos- sobre zonas expresamente reservadas en el Plan Comarcal. El Colegio de Arquitectos se opuso ya a la ordenación de una manzana afectada por el Plan Comarcal» (20).

El Plan Comarcal nació en virtud de la Ley de 3 de diciembre de 1953, que creó la Comisión de Urbanismo.

Al surgir ahora la EMMB se deroga aquella Ley de 1953, pasando las competencias de la Comisión a la nueva Entidad. Muchos técnicos opinan que con esta nueva disposición legal el Plan desaparece.

Tanto el Ministro de la Vivienda como el Gobernador civil han dicho lo contrario. El señor MARTín VILlA ha manifestado que «la Entidad no responde a la presión de los ricos para terminar con el Plan. La realidad urbanística de la comarca es tan exponente de las deficiencias que existen, que hay que resolver la situación atendiendo, eso sí, las legítimas reclamaciones y, por supuesto, lo que en su día pudieran dictaminar los Tribunales. La decisión política adoptada es continuar adelante con el Plan Comarcal, y será el nuevo ente el encargado de llevar estas directrices adelante» (21).

Sobre la posible revisión del citado Plan Comarcal, Udina MaRTORELL ve claro que dicha revisión debe quedar invalidada, toda vez que revisa un Plan aprobado por una Ley que ha sido derogada (22).

El reciente Decreto de 29 de noviembre viene a determinar que ala aprobación de la revisión del Plan Comarcal, actualmente en trámite, corresponderá, con carácter provisional, al Consejo Metropolitano, y con carácter definitivo al Organo desconcentrado del Ministerio de la Vivienda» (disposición transitoria quinta).

(20) «El Reglamento de la E. M. M., gran preocupación», El Correo Catalán, 21 septiembre 1974.

(21) Vid. La Vanguardia Española, Barcelona, 17 septiembre 1974, y Diario de Barcelona, 18 septiembre 1974.

(22) Vid. El Correo Catalán, 11 octubre 1974. 
Para quienes preguntan ¿qué pasará sin el Plan Comarcal?, Pedro Pascual apuntaba la posibilidad de que se esté procediendo a la redacción de un nuevo Plan, diferente del que actualnente se halla aún en período de audiencia a las Corporaciones. Por otra parte, no se descarta la posibilidad de que la EMMB, en vez de redactar el "Plan Metropolitano», asuma directa y totalmente el Plan Comarcal del 74 , pero en todo caso se plantea un grave problema: según claramente señala la Ley del Suelo, después de una suspensión de licencias - como ha ocurrido al aprobarse inicialmente el Plan Comarcal- no puede àcordarse otro en el mismo territorio, por causa de un nuevo plan, hasta después de cinco años. Cinco años que en el caso de Barcelona y comarca constituyen el sueño dorado de mucho especulador (23).

Algunos se lamentan de los años perdidos de planificación y relevos de técnicos y se preguntan ¿para qué habrá servido tanto presupuesto en las oficinas urbanísticas si tendremos que empezar de nuevo?

La causa de esto es para Udina Martorell que se han hecho muchos estudios de planificación y menos de estructura de los órganos metropolitanos. Y la planificación sin gestión no va a ninguna parte (24).

\section{Preocupación por el Reglamento de la EMMB}

El 30 de septiembre el señor Masó explicó que los Reglamentos se van a publicar por parte del Ministerio de la Vivienda y de Hacienda.

Es indudable la importancia del Reglamento. El citado R. Pradas ha escrito, recordando la frase de RoMANONES, «haced vosotros la Ley y dejadme a mí el Reglamento", "ya que estamos hablando de lo urbanístico, valga la pena recordar que el mayor handicap de la Ley del Suelo ha sido carecer de un Reglamento que hubiera podido hacerla operativa. Volviendo al tema, parece que las autoridades más directamente implicadas en la EMMB han entrado en una fase de estudio y preocupación por el Reglamento. La reciente coincidencia en Madrid de las primeras autoridades barcelonesas

(23) R. Pradas, «El Reglamento de la E. M. M., gran preocupación», El Correo Catalán, Barcelona, 21 septiembre 1974.

(24) Vid. El Correo Catalán, 11 octubre 1974. 
parece, a ojos de los observadores, que apunta, en gran parte, a resolver los problemas pendientes, y entre ellos el Reglamento. En definitiva, la EMMB, con todas sus limitaciones, será más o menos según el Reglamento".

Con posterioridad, el Decreto 3.276/1974, de 28 de noviembre, desarrolla el Decreto-ley 5/1974, y pone en funcionamiento los órganos de la EMMB, delimitando las competencias y modalidades de actuación de sus órganos con criterios de carácter descentralizador y subrayando la naturaleza esencialmente local del nuevo organismo, que viene a significar una modificación sustancial de los criterios que imperaron hasta ahora en el funcionamiento de los órganos administrativos de la comarca barcelonesa.

\section{ORGANOS RECTORES}

La EMMB estará regida por una Corporación municipal. Formarán parte de la misma:

a) El Consejo Metropolitano.

b) La Comisión Administrativa Metropolitana.

c) La Gerencia Metropolitana (a. 1.2.).

La composición y funciones de dichos órganos de gobierno serán las que se determinan en el presente Decreto-ley. En lo no previsto en él serán de aplicación las normas generales de Régimen local (a. 1.3).

\section{El Consejo Metropolitano}

\section{A) Concepto.}

El Consejo Metropolitano constituye el órgano superior de la Entidad y será elegido por todas las Corporaciones municipales integradas en ella y por la Diputación Provincial (a. 3.1).

\section{B) Representantes.}

Las Corporaciones municipales que integran el Consejo Metropolitano elegirán sus representantes en proporción a la respectiva población de cada uno de los Municipios. A estos efectos el Minis- 
terio de la Gobernación ha dictado normas para la elección de los miembros del Consejo Metropolitano de Barcelona y su Comisión Administrativa, por Decreto 2.863/1974, de 27 de septiembre.

Los miembros del Consejo Metropolitano de Barcelona y su número se distribuyen en los grupos siguientes, a efectos electorales:

1. Diez Consejeros representantes del Municipio de Barcelona.

2. Dos representantes por cada Municipio de más de $\mathbf{1 0 0 . 0 0 0}$ habitantes que formen parte de la EMMB.

3. Cuatro representantes por los Municipios de población inferior a 100.000 habitantes.

4. Seis Consejeros representantes de la Diputación Provincial de Barcelona (25).

El mandato de los Consejeros durará seis años, renovándose por mitad cada tres años.

La disposición transitoria primera, dos, dispone que: "Constituido el Consejo procederá acto seguido a la elección de los miembros que han de formar la Comisión Administrativa del mismon.

Según la disposición transitoria segunda: "En tanto no se realicen los ingresos de la EMMB a que se refiere el artículo 11 del Decreto-ley de su creación, los gastos necesarios para la constitución de dicho organismo serán anticipados, por partes iguales, por la Diputación Provincial de Barcelona y por el Ayuntamiento de la capital, sin perjuicio de su reembolso oportuno, con cargo a los futuros ingresos de la Entidad".

Aunque en la composición del órgano superior de la EMMB parece haberse procurado una representación lo más equilibrada de las Entidades locales, el Municipio de Barcelona ha de tene: una

(25) Los señores elegidos miembros del Consejo son los siguientes: por el grupo primero fueron elegidos por mayoria absoluta los Concejales señores Dot Bosch, Cañellas, Ganduxer, Abella, Güell, Blasi, Mir, Tormo, Traves y Quesada.

Por el grupo segundo: por Hospitalet de Llobregat resultaron elegidos su Alcalde, don Vicente Capdevilla, y el señor Vilaplana; por Badalona, su Alcalde, don Isidro Caballería, y don Antonio Lleal; por Santa Coloma de Gramanet, los elegidos fueron don Blas Muñoz y el Teniente de Alcalde don Juan Pérez Terol.

Por el grupo tercero fueron elegidos los Alcaldes de Cornellá, Molins del Rey, San Baudilio de Llobregat y Sardañola.

Por el grupo cuarto: los Diputados provinciales señores Matías de España, Ballesté, Zuazu, Allaina Caballero y Moreta.

El día 25 de noviembre prestaron juramento los nuevos miembros del Consejo de la Entidad, en el Salón de Ciento de las Casas Consistoriales, ante el Vicepresidente primero del Gobierno y Ministro de la Gobernación, don José Garcia Hernández, quien habló en el acto, exponiendo en una clara sintesis los orígenes, motivaciones y finalidades de la Entidad. 
representación cualificada y específica, ya que por razones hist6ricas y urbanísticas ostenta la condición de auténtica metrópoli.

Según el informe del Círculo de Economía, «La realidad demuestra que el factor que asegura el crecimiento y la obtención de niveles crecientes de riqueza individual y colectiva para el conjunto del Area, es la potencia de la plataforma de decisión que es y continuará siendo Barcelona.

Para que esta dinámica prosiga es preciso mantener y mejorar la ordenación territorial a nivel de Area, para lo cual se requiere el concurso y la participación de todas las comarcas que la integran hoy y de las que la integrarán en el futuro.

Con ello se minimiza el.papel de Barcelona, que ni tan sólo tiene la presidencia automática de la EMMB y cuya representación, fijada en diez representantes, es la mitad de lo que le correspondería por su población si la representación fuera proporcional» (26).

No obstante esto, mientras para algunos autores, como FUENTES Lojo (27), la representación del Municipio de Barcelona resulta excesiva y originará suspicacias por parte de los demás Ayuntamientos, para otros, Barcelona queda en situación minoritaria. Así opina ENTRENA CUESTA: "Lo curioso en este tema es que no sólo el Decreto-ley, sino en distintos medios de la opinión pública, se ha señalado que existe un predominio del Ayuntamiento de Barcelona; los números demuestran exactamente todo lo contrario. La comarca de Barcelona tiene hoy 2.800 .000 habitantes, de los cuales 1.800.000 pertenecen a Barcelona-ciudad. Esto quiere decir que, como los medios económicos de que dispondrá la Entidad se fijarán en proporción a los presupuestos municipales, la ciudad de Barcelona por sí sola pagará mucho más que el resto de Municipios, incluso cuando se extienda a éstos el régimen fiscal de aquéllos. $\mathrm{Y}$ sin embargo, habrá igual número de representantes de Municipios del resto de la comarca que del Ayuntamiento de Barcelona. La igualdad o equilibrio se establecería solo, ya con la nueva presencia

(26) El Círculo de Economía, entidad creada hace quince años y en la actualidad presidida por don Juan Mas Cantí, fue una de las primeras voces que señaló que es inútil la elaboración de un programa racional para la ciudad de Barcelona sin el previo reconocimiento legal del ente administrativo que contemple la totalidad del territorio como un todo orgánico, dotado de los medios de gestión, económicos y políticos, que aseguren la operatividad a todos los niveles.

Vid. los periódicos de Barcelona, Solidaridad Nacional, El Noticiero Universal, Diario de Barcelona y El Correo Catalán, del día 10 de octubre de 1974.

(27) FUENTES Lojo, aAnte el nuevo Decreto-ley sobre la creación de la Entidad Metropolitana de Barcelona», El Noticiero Universal, Barcelona, 6 septiembre 1974. 
de la representación municipal. Pero existe un aforismo jurídico según el cual la igualdad se establece tratando de forma desigual a desiguales, y si los barceloneses son más y pagan más, parece ser que habrán de estar más representados. Si a esto se añade la presencia de los representantes de la Diputación, quiere decir que el Ayuntamiento estará en minoría. Claro está que se trata de planteamientos formales, pues no existe motivo para suponer que vaya a darse un enfrentamiento entre representantes de Barcelona; por otra parte, Barcelona ya está acostumbrada a encontrarse en situaciones como la descrita» (28).

También para el ex Alcalde señor Porcioles, «Barcelona queda en posición gravemente minoritaria, tanto en el Consejo Metropolitano como en la Comisión Administrativa. Ni siquiera se atribuye a la ciudad de Barcelona, como en la Carta, su Presidencia. Por otra parte, se hacen intervenir en funciones municipales a organismos ajenos a esta competición, cuya potenciación debe buscarse en el área provincial y regional» (29).

Para MASo, el papel preponderante de Barcelona hay que juzgarlo como una conjunción y un respeto hacia los demás Municipios. Lógicamente, la ciudad de Barcelona está dispuesta a colaborar con todos ellos, a fin de conseguir un área más habitable y cómoda para todos. El Ayuntamiento de Barcelona no intenta en manera alguna pisar o arrinconar a los demás Municipios; al contrario, lo que desea es contribuir y colaborar con ellos y con la Diputación (30).

Formará parte, asimismo, del Consejo el Gerente metropolitano (a. 3.5).

Los elegidos habrán de pertenecer a las respectivas Corporaciones locales que representan, siendo electores los miembros de las Corporaciones que los designen (a. 3.4).

Aunque la doctrina ha defendido la conveniencia de que la elección de los miembros del Consejo fuera directa, con lo que los intereses municipales específicos quedarían diluidos en favor de una visión de conjunto de los problemas metropolitanos, el Decretoley, como se ve, opta por la elección indirecta a través de las representaciones de los entes locales afectados.

(28) Vid. El Correo Catalán, 22 septiembre 1974.

(29) Vid. La Actualidad Española, Barcelona, 7 septiembre 1974.

(30) Alfredo ReXACH, «Barcelona, una experiencia piloto: la E. M. M.», La ACtualidad Española, Barcelona. 


\section{C) Presidente.}

El Presidente del Consejo Metropolitano será nombrado y removido por Decreto, a propuesta del Ministro de la Gobernación, entre los Presidentes de las Corporaciones representadas en el mismo (a. 3.6), y cesará automáticamente cuando perdiera la condición de Presidente de la Corporación de origen.

En Consejo de Ministros celebrado en La Coruña fue nombrado Presidente del Consejo Municipal de la Entidad Metropolitana de Barcelona el Alcalde de la ciudad, don Enrique Maso, nombramiento que se estimó acertado, por la personalidad del señor Masó, hombre de una actividad incansable, de un realismo en el enfoque de los problemas muy necesario para la entidad que va a entrar en rodaje. Su labor, tan abnegada y eficiente en el Municipio testifican su entrega apasionada a la ciudad. Por otra parte, no hay que olvidar que la Entidad Metropolitana se crea como una consecuencia de la expansión de Barcelona, por lo que era lógico que la Presidencia se reservase a la persona que tiene sobre sus hombros la enorme responsabilidad de regir los intereses municipales de la Ciudad Condal y de encauzarlos con éxito.

Confluyen en don Enrique Masó unas cualidades excepcionales: visión rápida de los asuntos, concepción gerencial de los temas administrativos, amor al trabajo en equipo. Todo ello, junto a una cordialidad acusada, tan necesaria en el tratamiento de unos problemas delicados (31).

SAMARANCH se congratuló del nombramiento y dijo: "Creo que, personalmente, es el más indicado para la Presidencia del Consejo, aparte de que pienso que el Alcalde de Barcelona es quien debe presidir este órgano superior de la Entidad. Por ello, aprovecho la ocasión para felicitarle públicamente, al tiempo que ofrezco la total colaboración de la Diputación para lograr el óptimo funcionamiento de la Entidad Municipal Metropolitana»(32).

El Presidente del Ente Municipal Metropolitano será «nombrado y removido por Decreto». Ni siquiera tiene que ser forzosamente el Alcalde de Barcelona (también nombrado por Decreto, no se olvide).

(31) Vid. El Noticiero Universal, Barcelona, 31 agosto 1974.

(32) Vid. La Actualidad Española, 7 septiembre 1974. 
D) Posición del Alcalde de Barcelona dentro de la EMMB.

Los comentaristas se preguntarán ¿hasta qué punto el Alcalde Presidente contará con una asamblea totalmente favorable? $\mathrm{Y}$ de aquí parten estas deducciones: por un lado, los miembros del Consejo Metropolitano procedentes de Ayuntamientos distintos del de Barcelona actuarán con una cierta suspicacia ante el Alcalde de la gran ciudad; por similares motivos los de la Diputación; y en cuanto a los elegidos por el propio Ayuntamiento barcelonés, puede ocurrir que los Concejales sindicales votasen de manera compacta, provocando una mayoría sindical entre estos diez representantes. $\mathrm{Si}$ así fuera - y recordando aquella llamada "coalición sindical" que provocó en un pasado Pleno que se denegara un proyecto de aumento de impuestos que había sido presentado por el propio Alcalde-, el señor Masó vería muy cercenada su presencia en la Entidad. Por eso, quizá previendo el futuro, parece que se está hilando muy fino en cuanto a la figura del Gerente, pues es lógico que su papel será el más «efectivo» dentro de la Entidad.

\section{E) Competencias del Consejo y de su Presidente.}

El Consejo Metropolitano tendrá como competencias propias:

Uno. Redactar el planeamiento metropolitano y sus revisiones o modificaciones, en su caso.

El Decreto de 29 de noviembre se refiere a revisiones totales o modificaciones parciales y dice que el Consejo fijará las bases para la redacción del planeamiento y acordará su aprobación inicial y su aprobación provisional (a. 16).

Dos. Proponer, o,en su caso informar, normas complementarias y subsidiarias del planeamiento.

Tres. Informar, o en su caso redactar, los planes generales municipales de ordenación urbana.

Cuatro. Orientar e impulsar el desarrollo del planeamiento metropolitano.

Cinco. Aprobar el programa de desarrollo y ejecución del planeamiento metropolitano.

Seis. Recabar de los distintos Departamentos ministeriales, con competencias urbanísticas concurrentes, la formación del programa de actuaciones a que se refiere el artículo noveno. 
Siete. Aprobar un plan coordinado de establecimiento y prestación de servicios públicos de interés metropolitano y gestionarlos cuando proceda.

En este plan se delimitarán las respectivas competencias y responsabilidades de los distintos órganos participantes, a efectos de asegurar un efectivo y coordinado funcionamiento de los servicios en relación con los usos del suelo. La aprobación de dicho plan coordinado llevará aparejada la declaración implícita de utilidad pública prevista por el Decreto 10 de la Ley de Expropiación forzosa (a. 26, Decreto 29 de noviembre).

Ocho. Fiscalizar los actos de edificación y uso del suelo dentro del territorio de la EMMB y asesorar y asistir la actuación urbanística de los Municipios.

Nueve. Ejercer la potestad expropiatoria.

Diez. Adquirir y enajenar bienes y derechos y contratar obras y servicios cuando la cuantía de aquéllos y la duración o el total importe de éstos rebase los límites que reglamentariamente se establezcan.

Once. Constituir el patrimonio metropolitano del suelo y coordinar la gestión de los patrimonios municipales.

Doce. Subrogarse, previa aprobación del Ministerio de la Gobernación, en la competencia de los Municipios integrantes cuando no ejercieren adecuadamente sus obligaciones urbanísticas o su cometido exceda de sus posibilidades.

Trece. Aprobar las plantillas de personal y su remuneración de acuerdo con las disposiciones vigentes.

Catorce. Aprobar los presupuestos y sus modificaciones y las ordenanzas de exacciones y autorizar operaciones de crédito.

Quince. Cualesquiera otras competencias que resulten de lo dispuesto en este Decreto-ley (a. 4).

Por otra parte, el Consejo Metropolitano podrá solicitar, de los distintos Departamentos ministeriales con competencias urbanísticas, la formación de un programa de actuaciones, obras y servicios $\therefore$ que se propongan realizar en el ámbito del planeamiento metropolitano.

Según el artículo 10 del Decreto de 28 de noviembre, serán también atribuciones del Consejo Metropolitano:

a) La constitución del mismo y la elección de su seno de los vocales de la Comisión Administrativa. 
b) La promoción de Mancomunidades de Municipios y el informe de los expedientes de constitución de las mismas, cuando no las haya promovido.

c) La constitución, modificación y disolución de entes de gestión en común con los Ayuntamientos, y el informe de los expedientes cuando no haya intervenido en su promoción.

d) La aprobación provisional del Plan Director o Metropolitano y de los planes generales comarcales.

e) La aprobación definitiva de planes parciales, programas, ordenanzas, normas complementarias o subsidiarias del planeamiento y reglamentos de interés metropolitano.

f) La adquisición, enajenación, gravamen o arrendamiento de bienes y derechos cuando la cuantía rebase el 5 por 100 del presupuesto ordinario, y la concesión o contratación de obras y servicios cuya duración exceda de un año o su total importe rebase el 10 por 100 de dicho presupuesto.

g) La resolución de los recursos de alzada que con arreglo a la Ley del Suelo se interpongan en materia de urbanismo contra los acuerdos de los Ayuntamientos integrantes.

h) La propuesta de directrices para la descongestión de la zona metropolitana y el informe de las actuaciones urbanísticas que con esta finalidad se proyecten en otras áreas provinciales.

i) Cualesquiera otras atribuciones que resulten de lo dispuesto en este Decreto.

Corresponderá, igualmente, al Consejo emitir el informe sobre el Plan Provincial de Urbanismo que ha de redactar la Diputación Provincial con arreglo al artículo 14 del Decreto-ley 5/1974.

Para Lliset Borrell las competencias de la Corporación Metropolitana pueden ser de tres clases: propias, delegadas y de tutela.

Las primeras se extienden a todo proceso urbanístico en sentido integral.

La Corporación Metropolitana es además instrumento de coordinación de todas las actuaciones ministeriales a este nivel y deberá conocer los programas elaborados por los distintos Departamentos con incidencia en su territorio. La disconformidad de la Corporación con dichos programas avoca la competencia de su aprobación al Consejo de Ministros, con lo que se garantiza el no prevalecimiento de intereses sectoriales sobre los generales del área metropolitana. Dice LLISET: «Echamos de menos aquí la instru- 
mentación "anticipada" de la técnica de delegación a favor de la nueva Entidad, a conferir por los Ministerios para la realización metropolitana de obras o prestación de servicios estatales con transferencia de los medios financieros indispensables. Sería ésta una vía de potenciación de la Corporación Metropolitana, cuyos beneficios para el interés público parecen a todas luces evidentes.

Finalmente, las que hemos llamado competencias de tutela, que se ejercerán sobre los Municipios del área, tienen dos manifestaciones: asesoría y asistencia técnica a la actuación urbanística municipal, como verdadera acción de fomento de las Entidades de base, y subrogación en la competencia de éstas cuando no ejercieren adecuadamente sus actuaciones urbanísticas o su cometido exceda de sus posibilidades» (33).

Para Capdevilla Cardona, que como Alcalde de Hospitalet formará parte del Consejo Metropolitano, «las competencias del nuevo ente se reparten en dos grandes campos, el del planeamiento urbanístico metropolitano por un lado, y el de los servicios públicos de interés por otro. $\mathrm{Y}$ si bien estas dos grandes áreas eran también las de incidencia competencial de la desaparecida Comisión de Urbanismo y Servicios Comunes de Barcelona y otros Municipios, la diferencia entre ésta y el nuevo ente es sustancial, básicamente en función de que el nuevo ente es estrictamente municipal».

En cuanto a las competencias del Presidente del Consejo Metropolitano, el artículo 10 del Decreto de 29 de noviembre relaciona las siguientes:

a) Convocar, presidir, suspender y levantar las sesiones del Consejo y de la Comisión Administrativa y dirigir sus deliberaciones, pudiendo decidir los empates con voto de calidad.

b) Suspender la ejecución de las actas y acuerdos de la Corporación en los casos previstos en la Ley de Régimen local.

c) Corregir y sancionar las infracciones de los planes aproba-

(33) Vid. artículo citado en nota (14).

Para dicho autor la competencia de la Entidad Municipal Metropolitana de Barcelona es fundamentalmente urbanística. «EI urbanismo -escribe- es una actividad envolvente de las demás actividades públicas. No puede concebirse como un sector paralelo a los demás, sino transversal. Por esto, la creación de una entidad fundamentalmente urbanística ha de poseer una fuerza atractiva sobre las competencias incidentes en el área, originariamente ajenas, sobre todo si se ha configurado como una unidad de gobierno local. Consecuencia de lo cual es que, junto al núcleo de las competencias propias, su esfera de actuación se ha de extender tanto sobre los programas de los Departamentos ministeriales a ejecutar en el área, como sobre las competencias municipales defectuosamente ejercidas». 
dos con multas en la cuantía prevista en el artículo 215-2 de la Ley del Suelo.

d) La inspección de las obras y servicios de la Corporación.

e) Representar a la Corporación en toda clase de negocios jurídicos, pudiendo conferir mandatos para el ejercicio de dicha misión.

f) Dictar las normas que exija el mejor cumplimiento de los distintos servicios.

g) Comparecer en juicio y ejercitar acciones en caso de urgencia, dando cuenta a la Comisión Administrativa.

h) Nombrar y separar al Vicepresidente y a los directivos de servicios, oído el Gerente metropolitano en este último caso, y designar los Presidentes y miembros de las Comisiones que se constituyan.

i) La sanción de empleados de la Corporación cuando no esté reservada a otra autoridad.

j) Ejercitar todas las demás facultades de gobierno y administración de la Corporación no reservadas expresamente al Consejo o a la Comisión Administrativa, y las que aquél o ésta le deleguen.

k) Formar el orden del día de las reuniones del Consejo y de la Comisión Administrativa, así como de las Comisiones Administrativas.

\section{La Comisión Administrativa}

\section{A) Concepto.}

Como órgano competente de actuación de la EMMB funcionará una Comisión Administrativa, que elegirá el Consejo de su seno y que estará presidida por el que lo sea de la Corporación Municipal Metropolitana (a. 5.1).

\section{B) Composición.}

Su composición se integrará por dos Vocales representantes del Ayuntamiento de Barcelona, uno de la Diputación y tres de los restantes Ayuntamientos que componen la Entidad Municipal Metropolitana (a. 5.2).

Formarán también parte de la Comisión el Gerente metropolita- 
no, los Directores de servicios de la Corporación, el Secretario y el Interventor (a. 5.3), quienes tendrán voz, pero no voto.

El Presidente designará, de entre los miembros electivos de la Comisión, un Vicepresidente que le sustituya en caso de ausencia, vacante o enfermedad, y que lo será también del Consejo (a. 5.4).

Será aplicable a los componentes electivos del Consejo lo dispuesto para los Concejales en la legislación de Régimen local sobre incapacidades, incompatibilidades y causas de pérdida del cargo.

\section{C) Justificación.}

El Consejo Metropolitano alcanzará veintiséis miembros; no es, pues, de extrañar que dicho órgano superior se vea acompañado por una Comisión Administrativa -compuesta por seis miembros designados por el Consejo- como órgano de gestión permanente.

La necesidad de conciliar el principio democrático con la eficacia ha conducido a instrumentar la tecnificación de esta Comisión, además del órgano de la Gerencia, incorporando a la misma los directivos técnicos de los servicios generales - Gerente, Secretario o Interventor-y de los servicios finalistas - Directores de los Departamentos en que se estructure la Corporación-, en cuyas cualidades humanas y profesionales habrá de descansar la gestión metropolitana.

\section{D) Facultades.}

Son facultades de la Comisión Administrativa las siguientes:

Uno. Dirigir, con audiencia previa de los Ayuntamientos interesados, la elaboración de los planes y programas cuyo conocimiento corresponda al Consejo metropolitano.

Dos. Informar los demás asuntos que deban someterse a dicho Consejo.

Tres. Ejercer la potestad de organización de los servicios internos de la "Corporación» y nombrar, separar y jubilar a sus empleados de acuerdo con las disposiciones vigentes.

Cuatro. Proponer al Consejo, para su aprobación por la autoridad competente, normas complementarias y subsidiarias de planeamiento.

Cinco. Llevar a cabo la gestión del patrimonio metropolitano del suelo conforme a los principios que señale el Consejo. 
Seis. Desarrollar las directrices que en cada caso señale el Consejo Metropolitano en las materias de su competencia.

Siete. Cualesquiera otras que le delegue el Consejo (a. 6).

Según determina el artículo $7 .^{\circ}$ del Decreto de 29 de noviembre, a la Comisión Administrativa le corresponderán, además de las atribuciones que le confiere el artículo 6. del Decreto-ley 5/1974, las siguientes:

a) Adquisición de bienes y derechos o su enajenación, gravamen o arrendamiento por cuantía que exceda del 1 por 1.000 y no rebase el 5 por 100 del presupuesto.

b) Contratación o concesión de obras o servicios por plazos no superiores a un año y cuya cuantía exceda del 1 por 1.000 sin rebasar el 10 por 100 del presupuesto ordinario.

c) Interpretar los contratos administrativos y resolver las dudas que ofrezca su cumplimiento.

d) Aprobar definitivamente los proyectos de alineaciones y rasantes de ordenación de manzana, de urbanización y de compensación de volúmenes, siempre que estén de acuerdo con el plan general y, en su caso, con el plan parcial aprobado para el sector.

e) Informar las licencias para usos provisionales conforme al artículo 47-2 de la Ley del Suelo.

f) Desarrollo económico de los presupuestos aprobados, salvo las facultades de ordenación de pago.

g) Aprobación de conciertos fiscales y económicos, reconocimiento de exenciones, reducciones o bonificaciones tributarias y concesiones de fraccionamiento, aplazamientos o suspensiones de pago, con arreglo a la legislación común, salvo que se tratare de la aplicación particular de preceptos o acuerdos generales.

h) Ejercicio de acciones administrativas y judiciales sin perjuicio de las facultades del Presidente en caso de urgencia.

i) Nombramiento y jubilación de empleados, que se extenderá tanto al personal funcionario como al sujeto a la legislación laboral, de acuerdo con las normas establecidas y las plantillas aprobadas por el Consejo Metropolitano.

j) La incoación de expedientes disciplinarios a funcionarios y empleados, así como la suspensión previa de los funcionarios cuyo nombramiento corresponda a la Administración central.

k) La corrección de funcionarios que no sean de nombramien- 
to de la Dirección General de Administración Local, exceptuando la destitución o separación del servicio, que será competencia del Consejo.

\section{E) Sesiones del Consejo y de la Comisión Administrativa $y$ adopción de acuerdos.}

En el Decreto de 29 de noviembre se determina que el Consejo Metropolitano y su Comisión Administrativa celebrarán sus sesiones ordinarias y extraordinarias acomodándose a las disposiciones generales del Régimen local, sin más modificaciones que las siguientes:

a) Las sesiones ordinarias del Consejo y de la Comisión Administrativa tendrán lugar, al menos, una vez al trimestre para el primero, y una vez al mes para la segunda.

b) Las sesiones se celebrarán, en segunda convocatoria, veinticuatro horas después de la señalada para la primera.

c) En segunda convocatoria el número de miembros asistentes no podrá ser inferior a diez para el Consejo Metropolitano, ni a tres para la Comisión Administrativa.

d) Ninguna sesión podrá celebrarse válidamente sin la asistencia del Presidente, del Gerente y del Secretario de la Corporación o de quienes legalmente los sustituyan en el desempeño de sus cargos.

En las reuniones del Consejo Metropolitano en que se trate del programa de actuación, de la aprobación o de la liquidación del presupuesto, podrán ser convocados representantes de los Ayuntamientos correspondientes a los Municipios integrados en el ámbito territorial de la "Corporación» que no tengan representación directa en la misma, los cuales representantes tendrán voz, pero no voto, al tratarse de las aludidas materias (a. 8, Decreto 29 noviembre).

La adopción de acuerdos se ajustará a las normas generales de Régimen local.

Será preciso el voto favorable del número de miembros del Consejo o de la Comisión que determina el artículo 303 de la Ley de Régimen local para la validez de los acuerdos sobre las materias siguientes:

a) Modificación del ámbito territorial de la «Corporación». 
b) Creación o disolución de mancomunidades, consorcios, empresas mixtas u órganr especiales de gestión con personalidad propia.

c) Asunción de servicios de interés metropolitano que se vengan prestando por uno o varios Municipios integrantes o por consorcios.

d) Enajenación de bienes cuando su cuantía exceda del 10 por 100 del presupuesto ordinario de ingresos, sin perjuicio de las normas especiales aplicables al Patrimonio Metropolitano del Suelo.

e) Aprobación provisional de planes generales y definitiva de los parciales o especiales.

f) Concesiones o arrendamientos de bienes o servicios por más de cinco años y siempre que su cuantía exceda del 10 por 100 del presupuesto ordinario de ingresos.

g) Operaciones de crédito.

h) Destitución de funcionarios (a. 9, Decreto 29 de noviembre).

\section{La Gerencia Metropolitana}

\section{A) Concepto.}

La Gerencia Metropolitana será el órgano ejecutivo de la Comisión Administrativa, bajo la dependencia inmediata del Presidente de la misma, para el desarrollo de las funciones que a la Entidad Municipal Metropolitana competen (a. 7.1).

El Ministro de la Gobernación ha destacado la importancia de los papeles de la Gerencia en el acto de la toma de juramento de los nuevos miembros del Consejo, celebrado el 25 de noviembre.

\section{B) El Gerente.}

El Gerente será designado y removido, a propuesta del Consejo Metropolitano, por el Ministro de la Gobernación, oído el Gobernador civil de la Provincia (a. 7.2). El cargo será incompatible con el desempeño de cualquier otra función retribuida o relacionada con la Administración local o el urbanismo.

Es el primer cargo de esta naturaleza que surge dentro de la Administración municipal, y por ello no es fácil predecir su futuro. 
Parece ser que será como el Presidente de un Consejo ejecutivo formado por él y los Directores de servicios. Su importancia se deduce de las siguientes palabras de UdiNA MARTORELL: «Del acierto en escoger este cargo y la persona adecuada dependerá la extensión de la experiencia o el fracaso de la idea. El Gerente debe ser el brazo derecho del Presidente de la Entidad».

En este cargo el conocimiento de las complejidades de la problemática barcelonesa es un elemento importante, por lo que se ha apuntado que la persona llamada al mismo debe estar vinculada a Cataluña y con vivencias directas en sus problemas.

\section{C) Atribuciones del Gerente.}

Se dispone en el artículo 12 del Decreto de 29 de noviembre, que el Gerente tendrá, bajo la inmediata dependencia del Presidente, las siguientes atribuciones:

a) Ejecutar los acuerdos del Consejo y de la Comisión Administrativa.

b) Dirigir e inspeccionar la preparación del planeamiento y su desarrollo.

c) Vigilar e inspeccionar las obras e instalaciones y servicios.

d) Desarrollar la gestión económica y ordenar los pagos.

e) Realizar la contratación o concesión de obras y servicios no atribuidas a otros órganos.

f) Adoptar resoluciones de trámite.

g) Desempeñar cualquier cometido que le asignen las normas en vigor o le señale el Presidente del Consejo Metropolitano.

Además, el Gerente, con la aprobación del Presidente, designará al Director o Directores de servicios que hayan de sustituirle en caso de ausencia o enfermedad.

D) Direcciones de servicio y funcionarios.

El artículo 13 del Decreto de 29 de noviembre determina:

1. En inmediata relación con la Gerencia Metropolitana y sin perjuicio de las atribuciones que corresponden al Secretario y al Interventor, se organizarán las necesarias Direcciones de servicio 
en número no superior al de Vocales de la Comisión Administrativa a que se refiere el párrafo dos del artículo quinto del Decreto-ley.

2. Los Directores de servicios formarán parte de la Comisión Administrativa, con voz, pero sin voto, y ejercerán la jefatura irımediata de los servicios de la "Corporación» que le estuvieran encomendados, con las siguientes atribuciones:

1. ${ }^{\mathrm{a}}$ Dirigir y gestionar los servicios y resolver los asuntos que dentro de ellos les encomiende el Gerente.

2. Vigilar y fiscalizar todas las dependencias metropolitanas a su cargo.

3. ${ }^{a}$ Proponer al Gerente la resolución que estimen procedente en los asuntos que sean de competencia del mismo y cuya tramitación les está atribuida, respetando en todo caso las atribuciones conferidas a los demás órganos de la "Corporación».

4. ${ }^{\mathrm{a}}$ Elevar anualmente al Gerente un informe acerca de la marcha, coste y rendimiento de los servicios a su cargo.

3. El Presidente del Consejo Metropolitano, a propuesta del Gerente y atendiendo al interés de los servicios, podrá ampliar las facultades anteriormente enumeradas.

4. El cargo de Director de servicios será incompatible con el de miembro de la Entidad. Les afectarán las causas de incapacidad e incompatibilidad establecidas en los artículos 79 y $81-2$ de la Ley de Régimen local, y si se trata de funcionarios públicos, incluidos en la propia "Corporación», quedarán en la situación de excedencia especial que prevé el artículo 43 de la Ley Articulada de Funcionarios civiles de 7 de febrero de 1964.

5. Los Directores de servicios cesarán automáticamente al designarse nuevo Presidente de la "Corporación", sin perjuicio de que éste pueda confirmarles en sus cargos.

El Secretario de la «Corporación» tendrá el carácter y funciones que determina el artículo 140 del Reglamento de Funcionarios de Administración local, que ejercerá en la forma prevista por dicho texto reglamentario.

El Interventor de fondos de la "Corporación", como Jefe de los Servicios Económicos y asesor de la misma en materia económicofinanciera, asumirá las funciones que señalan los artículos 159 y siguientes del repetido Reglamento de Funcionarios de Administración local, que desempeñará en la forma prevista por dichas normas. 
Existirá, asimismo, un Depositario de fondos de la «Corporación» con el carácter y funciones que determinan los artículos 172 y siguientes del citado Reglamento.

Tanto el Secretario como el Interventor tendrán el carácter de miembros, con voz pero sin voto, del Consejo Metropolitano y de su Comisión Administrativa.

El Secretario, el Interventor y el Depositario de la «Corporación» serán designados entre funcionarios de los Cuerpos Nacionales respectivos y conforme al mismo procedimiento establecido en el artículo 28 de la Ley Especial del Municipio de Barceloria, texto aprobado por Decreto 1.166/1960, de 23 de mayo (a. 14, Decreto de 29 de noviembre).

Los cargos de Director de servicios, Secretario, Interventor y Depositario serán incompatibles con el desempeño de cualquier otra función retribuida relacionada con la Administración local o el Urbanismo (a. 15, Decreto de 29 de noviembre).

La integración de los funcionarios de la Comisión de Urbanismo y Servicios Comunes de Barcelona y otros Municipios en la aCorporación» se realizará con arreglo a las normas contenidas en la disposición transitoria segunda del Decreto de 29 de noviembre.

En tanto no se lleve a cabo la provisión de las plazas de Secretario, Interventor y Depositario de la "Corporación», la Dirección General de Administración Local podrá nombrarlos con carácter interino, a propuesta del Presidente.

\section{PLANEAMIENTO URBANISTICO Y SU EJECUCION}

\section{Contenido del planeamiento metropolitano}

El planeamiento metropolitano comprenderá:

a) Plan director o metropolitano, en su caso.

b) Plan o planes generales comarcales.

c) Planes parciales o especiales, en los casos que luego se indicará.

d) Proyectos de urbanización y demás fases de desarrollo del planeamiento parcial o especial en los supuestos del apartado anterior. 
e) Catálogo de edificios, conjuntos, paisajes, jardines, lugares y elementos de interés artístico, histórico, turístico, tradicional o de cualquier otra índole.

f) Normas complementarias del Plan General.

\section{A) Planes parciales.}

Los planes parciales o especiales serán redactados por la «Corporación", como parte del planeamiento metropolitano:

a) Cuando su realización no sea exigida por las necesidades propias y surgidas en el Municipio a que se refiera, sino por el ordenado desarrollo de la comarca. Además de los que se determinen en el futuro, se incluirán en este apartado los planes parciales y especiales correspondientes a los sectores de interés metropolitano o comarcal que se indiquen en el plan o planes generales.

b) Cuando afecten a más de un Municipio.

c) Cuando en el plazo que señalare la "Corporación» los Ayuntamientos interesados no los llevaren a cabo por su cuenta, aunque en tal caso deberá oírseles previamente.

d) Cuando lo solicite el Ayuntamiento afectado.

B) Catálogo de edificios, conjuntos, etc.

Los catálogos de edificios, conjuntos, etc., serán competencia de los Ayuntamientos respectivos cuando su interés sea puramente municipal. En cualquier caso deberán incluir las declaraciones de interés nacional y provincial, aprobadas por la Administración central y la Diputación Provincial, respectivamente.

C) Normas complementarias del Plan General.

Las normas complementarias del Plan General regularán aspectos secundarios de interés metropolitano del plan o planes generales, siempre que tales normas sean desarrollo de los planes generales y no estén en contradicción con los mismos. 


\section{COORDINACIÓN DE ACTUACIONES URBANÍSTICAS EN LA ZONA METROPOLITANA}

Para la coordinación de actuaciones urbanísticas dentro de la zona metropolitana se utilizarán:

1. El problema de la propia "Corporación» para el desarrollo y ejecución del planeamiento, en el cual se especificarán las sucesivas fases, hasta asegurar la efectiva utilización del territorio, de acuerdo con los objetivos previstos.

2. El programa de actuación, obras y servicios que se propongan realizar los distintos Departamentos ministeriales en el ámbito del planeamiento metropolitano.

3. Los programas de actuación, generales o urbanísticos, que formen en su caso los Municipios integrantes de la «Corporación» metropolitana.

La formación y aprobación de los programas se ajustará a lo establecido por la legislación aplicable en cada caso por el Decretoley 5/1974 (a. 18, Decreto 29 de noviembre).

En su función de orientar el desarrollo del planeamiento metropolitano, el Consejo aprobará normas de obligado cumplimiento para la redacción de planes, proyectos, reglamentos, ordenanzas y demás documentos integrantes del planeamiento y cuidará de que se cumplan las fases propuestas (a. 19, Decreto 29 de noviembre).

Independientemente de la formación del programa de actuaciones a que se refieren los números anteriores, cuando un órgano del Estado vaya a ejecutar alguno de los actos a que se refiere el artículo 165 de la Ley del Suelo, deberá ponerlo en conocimiento de la Corporación con arreglo a lo dispuesto en el artículo 167 de la citada Ley (a. 20.3, Decreto 29 de noviembre).

\section{Programa de actuaciones, obras y SERvicios}

El Consejo Metropolitano podrá solicitar de los distintos Departamentos ministeriales con competencias urbanísticas concurrentes, la formación de un programa de actuaciones, obras y servicios que se propongan realizar en el ámbito del planeamiento metropolitano. En los referidos programas podrá hacerse referencia a aque- 
llos servicios u obras cuya prestación o ejecución puedan, por su interés metropolitano, ser objeto de delegación en favor de la Entidad Municipal Metropolitana (a. 9.1).

En tales programas figurarán, con sus plazos correspondientes, las sucesivas fases de tramitación y ejecución de cada actuación, así como los correspondientes importes con el fin de coordinar las actuaciones y asegurar el desarrollo coherente de cada sector del ámbito metropolitano (a. 20.1, Decreto de 29 de noviembre).

Dichos programas determinarán, asimismo, aquellas obras o servicios cuya ejecución o prestación puedan, por su interés comarcal, ser objeto de delegación en favor de la "Corporación», y en especial los comprendidos en el programa de inversiones públicas que afecten a su demarcación territorial, de acuerdo con lo previstc en el artículo cuarto del texto refundido de la Ley del Plan de Desarrollo Económico y Social, aprobada por Decreto 1.541/1972 (a. 20.2, Decreto de 29 de noviembre).

Los programas formulados por los diversos Departamentos ministeriales, antes de su aprobación, se remitirán al Consejo Metropolitano. En caso de disconformidad, el Ministerio correspondiente los someterá a la decisión del Consejo de Ministros, previo informe del Ministerio de la Gobernación. El Consejo de Ministros decidirá si procede ejecutar el programa y, en este caso, ordenará, si fuera necesario, la iniciación del procedimiento, modificación o revisión del planeamiento metropolitano (a. 9.2).

No podrá fiscalizarse el gasto de obras de primer establecimiento que hayan de realizarse en el ámbito del planeamiento por los diversos Departamentos ministeriales, sus organismos autónomos y servicios estatales, sin que se acredite que dichas obras están incluidas en un programa sobre el que ha recaído informe favorable del Consejo Metropolitano de Barcelona o, en su caso, acuerdo favorable del Consejo de Ministros (a. 9.3).

\section{Competencia uRbantstica de los Ayuntamientos de la zona METROPOLITANA}

La competencia urbanística de los Ayuntamientos de la zona metropolitana comprenderá todas las facultades de índole local que no estén expresamente atribuidas a la «Corporación» por el Decretoley que la creó. 
Los Ayuntamientos redactarán los planes de ordenación y los proyectos de urbanización de sus respectivos términos municipales y los aprobarán inicial y provisionalmente como presupuesto para su aprobación definitiva.

La «Corporación» aprobará definitivamente todos los planes, proyectos y ordenanzas, así como sus modificaciones, que se formen para desarrollo del Plan General Comarcal.

La "Corporación» podrá, además, elaborar los planes de ordenación, catálogos y proyectos de urbanización:

a) Si no lo hicieren los Ayuntamientos respectivos en el plazo que al efecto se les señale, y $b$ ) Cuando lo solicite el Ayuntamiento afectado.

La ejecución del planeamiento urbanístico dentro de la demarcación de la zona metropolitana estará atribuida a la «Corporación» y a los Ayuntamientos integrados.

La fiscalización y vigilancia sè llevará a cabo por dicha «Corporación» en fases de aprobación, de desarrollo del planeamiento y de ejecución de las obras y comprenderá las medidas necesarias para hacer cumplir los planes aprobados.

En los casos de incorporación de nuevos Municipios, el Consejo Metropolitano deberá informar los planes generales municipales de ordenación urbana que se hallen en trámite posterior a la aprobación, y sin estar aprobados definitivamente, cuando se produzca dicha incorporación (a. 21, Decreto de 29 de noviembre).

\section{OTORGAMIENTO DE LICENCIAS URBANf́STICAS}

El otorgamiento de licencias urbanísticas corresponde a los res: pectivos Ayuntamientos.

Si transcurrieren los plazos señalados en el artículo noveno del Reglamento de Servicios de las Corporaciones locales sin que se hubiere notificado resolución expresa, el peticionario podrá acudir a la «Corporación» a los efectos prevenidos en dicho precepto.

Podrá, asimismo, la «Corporación» asumir la gestión, aunque no el gasto, para la expropiación de terrenos necesarios para las actuaciones de los Departamentos ministeriales y demás Entidades públicas, excepto cuando se trate de Ayuntamientos, salvo que éstos lo soliciten expresamente.

Corresponde, además, a la «Corporación» coordinar la gestión 
de los patrimonios municipales de suelo, conforme al programa de actuación del Plan General Comarcal y a las disposiciones complementarias que aquélla adopte con las siguientes finalidades:

a) Conseguir que se cumplan las previsiones sobre asignación de medios económicos para la formación de los patrimonios n:unicipales de suelo.

b) Canalizar la adquisición de terrénos hacia los sectores calificados de interés urbanístico preferente, $y$

c) Supeditar las enajenaciones del patrimonio al cumplimiento de los objetivos del Plan (a. 22, Decreto de 29 de noviembre).

6. COMPETENCIAS DE LA «CORPORACIÓN》 EN LA ACTUACIÓN URBANISTICA DE LOS MUNiCIPIOS

La «Corporación» asesorará y asistirá la actuación urbanística de los Municipios, cuando éstos lo soliciten, en alguna de estas formas:

a) Orientación económica y técnica.

b) Ayudas de igual carácter en la redacción de estudios, proyectos y planes.

c) Subvenciones a fondo perdido.

d) Ejecución de obras e instalación de servicios.

e) Anticipos económicos de carácter reintegrable.

$f)$ Cualesquiera otras que señalen los Ministerios de la Gobernación y de la Vivienda.

La asistencia se realizará preferentemente en favor de los $\mathrm{Mu}$ nicipios con menor capacidad técnica y económica (a. 23, Decreto de 29 de noviembre).

La competencia de la "Corporación" para fiscalizar los actos de edificación y uso del suelo dentro de su territorio se extenderá a los aspectos siguientes:

a) Tener conocimiento de todas las licencias de edificación, de uso del suelo o de las edificaciones que otorguen los Ayuntamientos, a cuyo efecto éstos vendrán obligados a trasladarle copıa de las mismas simultáneamente a la notificación a los particulares interesados.

b) Requerirá a los Ayuntamientos integrantes para que en el 
plazo de quince días informen detalladamente sobre determinadas licencias otorgadas o la ejecución de obras concretas.

c) Señalar a los respectivos Alcaldes las infracciones que los servicios de la «Corporación» observaren, y acordar por sí o encomendar a aquéllos, si procediere, la adopción de los remedios necesarios.

d) Adoptar las medidas oportunas, conforme a las disposiciones vigentes, para corregir las infracciones urbanísticas, con facultades para ordenar la paralización de las obras y el derribo de las realizadas en contradicción con los planes aprobados, así como para exigir responsabilidades e imponer sanciones conforme a los artículos 171 y 215 de la Ley del Suelo, a la Ley 158/1963, de 2 de diciembre, y al Decreto de 11 de junio de 1964.

e) Proponer al Gobernador civil la suspensión de aquellos acuerdos municipales en materia de otorgamiento de licencias que supongan manifiesta infracción legal.

La "Corporación" podrá conceder cédulas de calificación urbanística en las que se definirán las condiciones de edificación y uso de cada parcela y en las que se acreditará, en su caso, la condición de solar, de acuerdo con el artículo 67 de la Ley del Suelo. En el ámbito del territorio de la "Corporación" no podrán concederse licencias municipales de edificación ni de cualquier uso del suelo o de las edificaciones si a la solicitud no se acompaña tal cédula, cuando estuviere establecida en la forma prevista por la Ley del Suelo (a. 24, Decreto de 29 de noviembre).

Con la finalidad de prevenir, encauzar y desarrollar técnica y económicamente la expansión de las poblaciones de la zona, la "Corporación" constituirá su propio patrimonio del suelo y lo adscribirá a la gestión urbanística para la inmediata preparación y enajenación de interés colectivo y reserva de terrenos de futura utilización.

La adquisición de terrenos para constituir el Patrimonio Metropolitano del Suelo se verificará por cesión gratuita, compra o permuta, de acuerdo con la legislación vigente. También podrá efectuarse por expropiación forzosa, previa formación y aprobación por la «Corporación» del proyecto previsto en el artículo 73 y concordantes de la Ley del Suelo. Los terrenos adquiridos podrán estar situados fuera del territorio de la "Corporación" cuando así resulte necesario para el mejor cumplimiento de sus fines. 


\section{SERVICIOS PUBLICOS DE INTERES METROPOLITANO}

A los efectos del plan coordinado de establecimiento y prestación de servicios públicos que ha de aprobar el Consejo, se entenderá que son servicios de interés metropolitano los que se extiendan, con unidad de explotación o de destino, a varios Municipios comprendidos en el ámbito de planeamiento metropolitano, aunque sus instalaciones radiquen en un solo término municipal (a. 10.1).

La unidad de explotación o de destino podrá referirse a todo el ámbito metropolitano o a partes diferenciadas de él, determinadas por la modalidad de prestación del servicio de que se trate, por economías de escala o por otras circunstancias análogas.

En especial se considerarán servicios públicos de interés metropolitano, cuando concurran las circunstancias señaladas en los párrafos anteriores, los siguientes:

a) Transportes.

b) Abastecimiento de aguas.

c) Evacuación y tratamiento de aguas residuales.

d) Suministro de energía eléctrica y gas.

e) Fomento de la vivienda.

f) Destrucción y tratamiento de basuras.

g) Servicios funerarios con inclusión de cementerios.

h) Extinción de incendios.

i) Mataderos y mercados centrales (34).

j) Cualesquiera otros análogos o complementarios (a. 10.2).

1. TRANSFORMACIÓN DE SERVICIOS MUNICIPALES EN SERVICIOS DE INTERÉS METROPOLITANO

La transformación de servicios municipales en servicios de interés metropolitano comportará la modificación de la naturaleza jurídica del ente $u$ órgano gestor, si estuviere constituido, y la incorporación a éste de representantes de la "Corporación» o de los

(34) Con respecto a mataderos y mercados centrales, la zona metropolitana será considerada zona de influencia de aquéllos o de las unidades alimentarias que los agrupen, a los efectos de lo dispuesto en el Decreto mil quinientos sesenta/mil novecientos setenta, de 4 de junio, sobre ordenación de mercados mayoristas (Decreto de 29 de noviembre, art. 28, 2). 
Municipios afectados en la proporción que se establezca en relación con la responsabilidad económica asumida por las respectivas Corporaciones y en la forma que determine el Consejo (a. 27, 5, Decreto de 29 de noviembre).

\section{LA EMMB MÁs EFICIENTE EN CUANTO A SERVICIOS}

Según el Alcalde, la Entidad Municipal Metropolitana en algún aspecto será más eficiente no en cuanto a urbanismo, sino en cuanto a servicios. "Siendo urbanismo y territorio lo más importante, los servicios no dejan de ser menos importantes. El futuro lo hemos de planificar fuera de la comarca; dentro de la comarca hemos de buscar el buen vivir con lo que tenemos».

\section{3. ¿QUIÉN PAGARA LOS SERVICIOS?}

El señor Masó dijo en su discurso del último día de septiembre: «Mucho se puede hacer a través de este Decreto-ley, por lo que atañe a los servicios en la comarca; Barcelona financia un conjunto de servicios que ya son metropolitanos». Y dividió en tres partidas fundamentales el dinero de la ciudad: la Hacienda pública municipal, que es lo típico, propiamente del Ayuntamiento; concesiones, como túneles del Tibidabo, la incineradora de basuras, etc., y los servicios municipales, como transporte de superficie, metro, etc. Sólo en estos servicios, la estimación de deudas del $\mathrm{Mu}$ nicipio barcelonés en diciembre de 1974 es de 6.102 millones de pesetas.

Ya que el Alcalde, con buen criterio, considera una prioridad a la necesidad de dejar los servicios para «bienvivir», surgió la lógica pregunta de quién los iba a pagar. Barcelona tiene un déficit de más de cuarenta mil millones de pesetas; Santa Coloma de Gramanet, Badalona, Hospitalet, San Adrián de Besós y los restantes Municipios de la comarca suman también decenas de miles de millones de pesetas de déficit, no sólo de capitalización de servicios, sino de deudas; por otro lado, el ente metropolitano sigue la misma tónica de las carreteras catalanas, de en lugar de adaptarlas a las necesidades del contribuyente, se le montan autopistas de peaje 
paralelas, y por tanto el ente no está contemplado en los Presupuestos Generales del Estado.

En el acto de la toma de juramento de los miembros del Consejo, el señor Masó dijo que toda la problemática de los servicios en la comarca debe ser estudiada de una manera comunitaria en todo su conjunto: transportes, basuras, cementerios, distribución de agua, etc. Expresó su confianza en que dentro de estos servicios "uno muy importante, el de la traída del agua del Ebro, será estudiado y realizado en lo que a nosotros competa con todo el cariño y toda la dedicación que se merece el que se solucione esta necesidad vital para todos nuestros habitantes".

En el mencionado acto destacó el Ministro de la Gobernación la importancia que tendrá el plan combinado de servicios de interés metropolitano, cuyas inversiones se declaran incluidas en el Plan de Desarrollo (35).

\section{El SERVICIO DE TRANSPORTES URBANOS}

El transporte es un ordenador del territorio y en verdad los planes de urbanismo para extensas zonas deben suplementarse con planes de transportes, pues transportes y urbanismo son interdependientes.

Al considerar el Decreto-ley que comentamos los transportes como servicio público de interés metropolitano, se abren a estos servicios nuevas perspectivas.

Se ha escrito recientemente que:

«La concentración del transporte bajo la misma dirección supone de por sí una mayor coordinación en líneas de la red: las de transporte subterráneo con las de superficie, tanto urbanas como interurbanas, dejando al margen algunos de los problemas actuales en esta materia; por otra parte, se suprimirian duplicaciones de recorrido, se llegaría a la creación de economías externas al aumentar los beneficios sociales en cuanto puedan reducirse los tiempos de desplazamientos, la fatiga producida por los mismos, potenciación de áreas obsoletas, se podría llegar a conseguir mayores índices de calidad, de frecuencias, a lograr horarios más flexibles y acomo-

(35) Vid. La Vanguardia Española, Barcelona, 21 de septiembre y 26 de noviembre de 1974. 
dados a las necesidades que se plantean, todo ello se reduce al problema de la coordinación» (36).

La EMMB ha supuesto un paso adelante y requerirá en este aspecto un mecanismo que se ha de poner en movimiento para el montaje de una gran empresa pública que asuma bajo una misma autoridad su gestión en el territorio de la Entidad, con vistas a unificar tarifas, coordinar horarios, etc.

Se ha hecho énfasis sobre los transportes urbanos, justificando que una de las necesidades más imperiosas para la ordenación y desarrollo de la EMMB será estructurar los servicios de transportes urbanos, planificando una red de comunicaciones eficiente (37).

Existe un vínculo estrecho entre los servicios que requiere un territorio y la extensión de éste bajo la jurisdicción de los organismos administrativos y gubernamentales de la metrópoli. Como a medida que se desarrolla la técnica del transporte se exticnde la zona de influencia de la metrópoli, es imposible, desde el punto de vista práctico, a una sola administración cubrir todo el territorio que corresponde a la zona de influencia de la metrópoli. Por eso se recurre a dos tipos de soluciones de compromiso:

a) Definir los límites de la metrópoli con el fin de controlar su expansión natural y de tender a la formación de un único territorio urbano por la absorción simultánea de territorios altamente urbanizados.

(36) María de los Angeles Gil Estallo y José Falles Ferrer, aAreas y servicios públicos. El transporte colectivo en la E. M. M. de Barcelonas, Tele-Expres, 7 noviembre 1974.

(37) En La Vanguardia Española se ha escrito: «Si, el condicionante de los transportes urbanos debe tener prioridad.

A la compañía municipalizadora, que además tiene el dominio de «Urbas», le correspondería una planificación que fundiera en un bloque los servicios de ambas empresas. Quizá así no se duplicarían gastos porque de los 45 millones de kilómetros recorridos por los autobuses de Barcelona, algunos podrían reducir los 12 millones recorridos por los autobuses de "Urbas".

Los transportes de Barcelona tienen una flota de 855 autobuses, que atienden 72 líneas con una longitud total de 374 kilómetros. «Urbas» dispone de 147 vehículos y sirven solamente a 28 líneas con una longitud de 566 kilómetros. La empresa barcelontesa tuvo un déficit de 462 millones en 1973, arrastrando además otras deudas que capitalizarán unos 3.000 millones de pesetas a final de 1974 y in cuya partida también debe sumarse cuentas de los servicios de «Urbas».

Existen dos poderosas razones para ahondar en una nueva planificación de los transportes urbanos. La primera como ordenación de servicios de comunicaciones de innegable valor social, y la segunda para repartir las cargas de déficit que este servicio pueda reportar.

El Area Metropolitana puede ser ente ideal para hacer viable el plan». 
b) Revisión de medios para solucionar los problemas de los suburbios, que están por las funciones estrechamente asociados, pero no integrados en la metrópoli (38).

En materia de transportes mecánicos por carretera, cuando el itinerario de los mismos no se desarrolle en su totalidad en el ámbito del planeamiento metropolitano, el Consejo podrá solicitar del Ministerio de Obras Públicas el traspaso de competencias, fundamentado en el principio de unidad de explotación o de destino. Si el Ministerio discrepase de tal apreciación, se someterá el caso a resolución del Consejo de Ministros (a. 28.1, Decreto de 29 de noviembre).

5. FACUltades de LA «CORPORACIÓN» EN RELACIÓN A DiCHOS SERVICIOS

La Corporación Municipal Metropolitana, en relación con el establecimiento y prestación de los servicios de interés metropolitano, tendrá las siguientes facultades:

a) Promover la constitución de Mancomunidades de Municipios.

b) Constituir, en común con los Ayuntamientos, entes de gestión.

c) Establecer consorcios con los Ayuntamientos afectados o con el Estado $\mathrm{u}$ otros entes públicos.

d) Informar los expedientes de constitución de Mancomunidades, entes de gestión y consorcios, cuando no haya intervenido en su promoción.

e) Asumir el establecimiento y prestación del servicio, previa audiencia durante un mes de las Corporaciones municipales afectadas. El acuerdo de la "Corporación» podrá ser recurrido por los Ayuntamientos ante el Ministerio de la Gobernación.

f) Prestar asistencia técnica a los Municipios y, en todo caso, inspeccionar los servicios de interés metropolitano.

g) En materia de transportes mecánicos por carretera, ejercer las competencias que la legislación especial atribuya a la Adminis-

(38) Vid. Problemas de las Areas Metropolitanas, pág. 149. 
tración del Estado, siempre que se trate de servicios cuyo itinerario se desarrolle en su totalidad en el ámbito del planeamiento metrópolitano (a. 10.3).

Para dar cumplimiento a lo dispuesto en este apartado, en cuanto al traspaso de competencias en materia de transportes mecánicos por carretera, determina la disposición cuarta de las finales que el Consejo Metropolitano, en el plazo de un año a contar desde la fecha de su constitución, elaborará un Plan con arreglo al cual haya de hacerse dicho traspaso y forma en que quedarán ordenadus los mencionados transportes, sometiéndolo a la conformidad del Ministerio de Obras Públicas. En caso de disconformidad de dicho Ministerio al Plan referido, resolverá definitivamente lo que proceda el Consejo de Ministros.

\section{A) Asistencia técnica de la "Corporación» a los Municipios.}

La asistencia técnica de la «Corporación» a los Municipios que la componen en materia de instalación y prestación de servicios, se regirá por normas análogas a las establecidas en el artículo 23 del Decreto de 29 de noviembre sobre actuación urbanística.

B) Trámite para la asunción del establecimiento y prestación de un servicio concreto.

Tal asunción se hará mediante propuesta de la Comisión Administrativa, audiencia durante un mes de las Corporaciones interesadas y acuerdo aprobatorio del Consejo Metropolitano, recurrible ante el Ministerio de la Gobernación.

La propuesta de la Comisión Administrativa comprenderá los siguientes extremos:

a) Justificación del carácter metropolitano del servicio, salvo que éste figurara ya incluido como tal en el plan coordinado.

b) Modalidad de prestación y medidas jurídicas que, en su caso, sean menester para la implantación, coordinación y sostenimiento del servicio.

c) Coste de implantación y funcionamiento y fórmula económica de financiación (a. 27, Decreto de 29 de noviembre). 


\section{V̀II. REGIMEN FINANCIERO DE LA «CORPORACION"}

La importancia del régimen financiero de la EMMB se desprende de las siguientes palabras de Udina Martorell: "La Entidad Municipal Metropolitana de Barcelona está ahí con estructura suficiente con amplias competencias, con perspectivas de actuación trascendente, pero sin recursos suficientes de orden económico.

La esperanza que puede suscitar, por encima de la decepción inicial, su situación depende, en primerísimo lugar, del plańteamiento y solución eficaz del problema de la hacienda metropolitana» (39).

\section{INGRESOS}

La EMMB estará dotada con los ingresos siguientes:

Primero. Las rentas y productos de su patrimonio y el rendimiento de los servicios para cuya explotación está autorizada.

Segundo. Las subvenciones y auxilios concedidos por el Estado, la Diputación y los Municipios y los donativos de otras Entidades o particulares.

Esta «importante subvención» del Estado figurará en la partida correspondiente del Presupuesto de gastos del Ministerio de la Gobernación.

Según la disposición transitoria tercera del Decreto de 29 de noviembre, "hasta tanto se fije la subvención estatal que resulte precisa para el debido funcionamiento de los servicios de la "Corporación", ésta percibirá, como mínimo, el 80 por 100 de la que tenía asignada hasta ahora la Comisión de Urbanismo y Servicios Comunes de Barcelona y otros Municipios».

Tercero. La aportación de los Ayuntamientos integrados en la EMMB en la forma establecida por este Decreto-ley.

El Ministro de la Gobernación, en el citado acto de toma de posesión, informó que la hacienda metropolitana se nutrirá de "una importante subvención con cargo al Presupuesto del Estado» y de otra con la aportación de los propios Ayuntamientos inte-

(39) Udina Martorell, «Problemática de la Hacienda Municipal Metropolitana», El Noticiero Universal, 9 septiembre 1974. 
resados, que oscilará entre el 3 y el 10 por 100 de sus presupuestos, a la que se unirá también la Diputación Provincial, con un 3 por 100 de sus presupuestos (40).

Cuarto. Las exacciones autorizadas por la Ley en razón de las obras y servicios realizados por la Entidad y las que, en todo o en parte, pueden cederle los Municipios por la misma razón.

Quinto. Cualesquiera otros que les corresponda percibir de acuerdo con las leyes (a. 11).

En aras de un afán simplificador, Rovira Mola estima difícilmente practicable la prevención de este artículo, en el sentido de incluir entre los ingresos de la EMMB las exacciones que en todo o en parte pueden cederle los Municipios por razón de obras y servicios. Podría aceptarse una cesión configurada en forma de asignación total o parcial de rendmiento en la hipótesis muy improbable de que los Ayuntamientos accedieran voluntariamente a ello, pero debe rechazarse una cesión de la gestión. Concebida y estructurada la EMMB con un exquisito respeto a las potestades tributarias de los Municipios integrados, no se ve la necesidad, ni siquiera la oportunidad, de sobreponer otro nivel de administración fiscal, que sólo estará justificado si aquello dispusiera - y no es el caso- de algún impuesto metropolitano desconocido en la fiscalidad local.

$Y$ añade: "a no ser que se pretendiera con atrayentes incentivos económicos desmantelar las disposiciones fiscales de algún o algunos Ayuntamientos de la EMMB, realizando un trasvase a ésta de determinados elementos personales de las respectivas Administra. ciones".

Según el citado Informe del Círculo. Económico: «No se establece un mecanismo claro que dote a la EMMB de un presupuesto propio y adecuado".

Para cubrir, en la parte procedente, los presupuestos de la EMMB, los Ayuntamientos comprendidos en la misma contribuirán anualmente mediante una aportación calculada sobre el importe de sus presupuestos ordinarios, que fijará el Ministerio de la Gobernación y cuyos límites máximo y mínimo y forma de determinarlos se establecerán por Decreto a propuesta del mismo Ministerio (a. 12).

(40) Vid. La Vanguardia Española, 26 noviembre 1974. 
Para Udina Martorell (41), la Entidad la pagarán quienes vivan en ella. "Lo cual no quiere decir que no haya aportaciones del Estado en forma de subvención o participación de recursos, teniendo en cuenta la importancia y densidad de población de la Entidad».

\section{EXTENSIÓN DEL RÉGIMEN FISCAL DE BARCELONA}

Las especialidades del régimen fiscal del Municipio de Barcelona se aplicarán también a los demás comprendidos en la EMMB (a. 13.1).

Dicha aplicación tendrá lugar con carácter automático una vez que se constituya la Corporación Municipal Metropolitana de Barcelona (a. 13.2).

Los Ministerios de Hacienda y de la Gobernación podrán adoptar las medidas que sean precisas para el cumplimiento de lo dispuesto en este artículo (a. 13.3).

Para Masó esto va a significar un ingreso adicional muy importante para todos los Municipios, excepto el barcelonés, porque ya los tenía antes $\mathrm{y}$, en consecuencia, no va a mejorar.

Rovira Mola escribe: "Esas disposiciones, ante la relativa anfibología de la expresión "especialidades del régimen fiscal", podrian afirmar tranquilamente que son "especialidades del sistema tributario". Manifestándose así, estarían en la línea de la desconcentración que, al menos a falta de una clara descentralización, anima el espíritu y el contexto del Decreto-ley; y para las demás 27 Corporaciones locales comprendidas en la EMMB se desvanecería el fantasma de una complicación administrativa, cuya aparición cabe sospechar y temer con un entendimiento técnico ericastillado, por añadidura, en un artículo 13»(42).

(41) La región catalana paga anualmente a la Administración más de $45.000 \mathrm{mi}$ llones de pesetas. A cambio, autofinancia los costes de su demografía, recepción de inmigración y déficit de infraestructuras básicas. UdiNa opina que los recursos de los Presupuestos del Estado deben repartirse y que las zonas de más alto nivel de renta deben contribuir a las cargas comunes del país.

El problema es de insuficiencia de medios. Es de general conocimiento que la participación en el Producto Nacional Bruto es en la Administración local muy limitada: ligeramente por encima del 3 por 100, la mitad o un tercio de lo que supone en la mayor parte de los países europeos. (Vid. El Correo Catalán, 11 octubre 1974).

(42) Alberto Rovira Mola, «La Entidad Municipal Metropolitana debe financiarse por la subvención del Estado y de los Municipios integrados", Diario de Barcelona, 14 septicmbre 1974. 
Y añade que así desaparecería a la vez una homogeneidad procesal en cierto modo deseable, y solamente la ciudad de Barcelona mantendría hilo fiscal directo con el Ministerio de Hacienda.

Para Fuentes Lojo la aplicación automática de las especialidades, en cuanto al régimen fiscal del Municipio barcelonés a los demás Municipios de la EMMB, puede ser una medida demasiado tajante, en especial cuando la economía de las empresas es deficitaria.

Para Udina la extensión a los otros veintisiete Municipios metropolitanos barceloneses del sistema fiscal de la metrópoli reforzará en alguna medida el ingreso total del presupuesto consolidado.

Según Rovira Mola: "Si las especialidades del régimen fiscal del Municipio de Barcelona han de aplicarse también a los demás comprendidos en la EMMB, hay motivos para abogar por una uniformidad tributaria municipal a lo largo y ancho de la jurisdicción metropolitana. Al menos teóricamente sería deseable. No obstante, concurre una circunstancia - a mi entender de mucho peso- que aconseja perfilar el uniformismo con ciertos ribetes de relatividad. Me refiero a las desigualdades de renta existentes en los distintos Municipios, tanto de que se trate de renta producida, percibida o consumida. El conjunto de poblaciones que constituyen la EMMB ofrecen una notoria heterogeneidad".

$\mathrm{Y}$ añade que el régimen de paridad fiscal en términos de uniformidad absoluta con Barcelona conduciría probablemente a acentuar las desigualdades de renta (43). Sería, pues, conveniente ajustar la regulación de las exacciones municipales a la normativa de Barcelona, respetando las peculiaridades de cada término y con la excepción de los tipos de gravamen, porque si éstos, en el Reglamento de Hacienda Municipal de Barcelona, se caracterizan en cualquier caso por ser máximos, debería conservarse para los veintisiete Municipios afectados la posibilidad autonómica de elegir el tipo más adecuado.

No falta quien, como Wifredo EsPINA, se pregunte si esta ampliación fiscal será legal, es decir, ¿en virtud de qué disposición se podrán hacer obligatorias a todos los Municipios que queden dentro de la EMMB las tributaciones que la Carta especial de Barcelona vino a establecer para los barceloneses? Y sostiene que a su

(43) Alberto Rovira Mola, «En torno a la financiación de la Entidad Municipal Metropolitana de Barcelona. El reto fiscal de 27 Municipios", Diario de Barcelona, 14 septiembre 1974. 
juicio esta ampliación fiscal es ilegal, ya que el Decreto-ley no ha sido "votado en Cortes", como dispone el Fuero de los Españoles que lo sea toda disposición que establezca la obligación de "pagar tributos» (44).

Cuando alguno de los Municipios integrantes de la "Corporación" no cumpliera debidamente lo dispuesto en el artículo 13 del Decreto-ley 5/1974, la "Corporación» lo pondrá en conocimiento del Ministerio de la Gobernación, que dará traslado al de Hacienda, proponiéndole las medidas a adoptar, entre las que podrán figurar la transferencia a la "Corporación» de la recaudación de los recursos de que se trate. El acuerdo se dictará conjuntamente por ambos Ministerios (a. 24, Decreto de 29 de noviembre).

La gestión tributaria de las exacciones podrá ser asumida por la "Corporación» o delegada en los Ayuntamientos.

La aprobación de las Ordenanzas fiscales y de los Presupuestos de la "Corporación", así como las demás facultades de fiscalización en materia económica atribuidas a los Delegados de Hacienda. serán ejercidas, en el caso de la "Corporación", por la Dirección General del Tesoro y Presupuestos, previo informe de la de Administración Local.

Los acuerdos que el Consejo Metropolitano adopte sobre imposición y ordenación de exacciones y sobre presupuestos se comunicarán, antes de ser expuestos al público, a los Ayuntamientos de la "Corporación", para que formulen las oportunas alegaciones, que informará la Comisión Administrativa y resolverá el Consejo Metropolitano.

Serán aplicables a la «Corporación», con carácter supletorio, el Reglamento de Hacienda Municipal de Barcelona vigente, así como sus disposiciones complementarias.

La "Corporación» podrá acudir al crédito local, y la Deuda emitida por la misma, siempre que lo autorice el Ministerio de Hacienda, gozará de los mismos beneficios que la Deuda Pública del Estado a los efectos de constitución de fianzas, reservas obligatorias e inversiones de Entidades de Previsión, Seguros y Ahorro.

(44) Vid. El Correo Catalán, Barcelona, 22 febrero 1974. 


\section{DIPUTACION PROVINCIAL Y PLAN PROVINCIAL DE URBANISMO}

Se encomienda a la Diputación Provincial de Barcelona la redacción del Plan Provincial de Urbanismo y las funciones y cometidos actualmente atribuidos a la Comisión gestora de los trabajos para la formación del Plan de Ordenación del Area Metropolitana de Barcelona, quedando suprimida dicha Comisión (a. 14.1).

Las competencias y funciones atribuidas a la Diputación Provincial en el párrafo anterior se extenderán exclusivamente al territorio provincial fuera del ámbito de la EMMB (a. 14.2).

Esto supone la desaparición del proyecto del Area Metropolitana, ya que de hecho la extensión territorial a la que se extenderá la competencia de la EMMB es sensiblemente menor que la prevista por el Area, que debía abarcar 162 Municipios (la EMMB sólo abarca por ahora 28), aunque según el Decreto-ley el ámbito de la EMMB puede ser ampliado.

En el corto período de un año la Diputación Provincial ha pasado de tener una vida poco relevante y bastante pasiva a una posibilidad de protagonismo que la EMMB ha favorecido.

Hay que señalar que según el Decreto-ley, todo el territorio - de gran extensión- que no recoge la Entidad pasa a clepender urbanísticamente de la Diputación, que tiene asimismo a seis de sus miembros en el Consejo Metropolitano.

Según SAMARANCH, "en la filosofía de este Decreto-ley hay una llamada a la buena voluntad, a la colaboración entre las Corporaciones locales de la Provincia». Dice que en la EMMB la Diputación tendrá una representación cualificada, con la que naturalmente «colaboraremos con todos los Municipios, y muy especialmente con el de Barcelona, que es el que tiene problemas más ingentes. En cuanto al resto de la Provincia, queda en manos de la Diputación la planificación de la misma. A mí -dice Samaranch-, desde el punto de vista político, me atrae la idea de que la Corporación Provincial pueda participar en la planificación de la Provincia, tan necesaria para que no se degrade, como hemos visto suceder en ciertas ocasiones» (45).

En el Plan que la Diputación Provincial elabore, conforme al párrafo uno de este artículo, se dará audiencia a la EMMB (a. 14.3).

(45) Vid. La Actualidad Española, Barcelona, septicmbre 1974. 
Para las zonas comprendidas en dicho Plan, la Diputación Provincial de Barcelona podrá proponer, también con audiencia del Consejo Metropolitano, la aprobación de normas complementarias y subsidiarias de planeamiento para que rijan en tanto se lleve a cabo la aprobación de éste, sin perjuicio de la aplicabilidad del artículo 22 de la Ley sobre Régimen del Suelo y Ordenación urbana relativo a suspensión de licencias (a. 14.4).

La aprobación de tales normas complementarias y subsidiarias corresponderá al Organo a que se refiere el artículo siguiente (a. 14.5).

Muchos piensan que no tardarán en sumarse a la EMMB otros Municipios y comarcas, y ante la duda de ¿quién cuidará de que no empiece una nueva especulación a gran escala en esos Municipios y comarcas?, se ha señalado que en parte esta acción puede suplirla la Diputación Provincial, que está facultada para planificar en el resto de la Provincia (46).

\section{ORGANO DESCONCENTRADO}

Las competencias que tiene atribuidas el Ministerio de la Vivienda en materia de urbanismo por la legislación vigente, en cuanto afecte a la Provincia de Barcelona, serán ejercidas por un Organo desconcentrado, que dependerá administrativamente de dicho Ministerio. Dicho Organo estará presidido por el Gobernador civil, siendo Vicepresidente el Director general de Urbanismo, y formarán parte del mismo el Delegado provincial del Ministerio de la Vivienda, el Gerente de la EMMB, un representante de cada uno de los Ministerios de Hacienda, Gobernación, Obras Públicas, Educación y Ciencia, Industria, Comercio, Vivienda, Información y Turismo y Planificación del Desarrollo, un representante de la Organización Sindical nombrado por el Ministro de Relaciones Sindicales y dos miembros expertos en urbanismo designados por el Ministerio de la Vivienda, el que también nombrará un Secretario que asistirá al Organo con voz y voto (a. 15.1).

La aprobación definitiva de los Planes generales y del Plan metropolitano se acordará por el Organo a que se refiere el párrafo anterior (a. 15.2).

(46) Vid. El Correo Catalán, Barcelona, 11 octubre 1974. 
Las funciones de tutela que $\in \mathfrak{n}$ materia urbanística tienen atribuidas en la legislación vigente el Ministerio de la Gobernación y el de la Vivienda serán ejercidas por ellos en la forma establecida en lo que no resulte modificado por el presente Decreto-ley (a. 15.3).

\section{Competencias}

La disposición segunda determina:

Uno. Las competencias que en la actualidad están atribuidas a la Comisión de Urbanismo y Servicios Comunes de Barcelona y su Comarca pasarán a ser ejercidas por la EMMB y por el Organo desconcentrado a que se refiere el artículo 15 de este Decreto-ley, de acuerdo con lo dispuesto en el mismo, quienes asumirán, en razón a su diversa naturaleza, los derechos y obligaciones que dicha Comisión tenga contraídos.

Dos. Las funciones de la Comisión Provincial de Urbanismo de Barcelona se transferirán al Organo desconcentrado que regula el mencionado artículo 15, de conformidad con lo establecido en este Decreto-ley.

\section{CRiticas}

Sobre este Organo desconcentrado se ha levantado una viva polémica. Fuentes Lojo (47) lo ve como positivo, "porque permitirá agilizar la solución de muchos problemas al otorgársele las competencias que tiene atribuidas el Ministerio de la Vivienda en materia de urbanismo".

El Ministro de la Gobernación, señor Garcfa HeRnÁndeZ, destacó recientemente que los planes parciales y los proyectos de urbanización redactados por los Ayuntamientos y aprobados provisıonalmente por los mismos, lo serán con carácter definitivo por la EMMB, es decir, por los propios Ayuntamientos integrados en ella. Esta facultad estaba hasta ahora reservada a los Organos de la Administración Central del Estado.

ENTRENa CuEsta estima que la creación del organismo debe considerarse como un acierto (48); aunque posteriormente ha dicho

(47) Vid. La Vanguardia Española, Barcelona, 26 noviembre 1974.

(48) Vid. Diario de Cataluña, Barcelona, 8 septiembre 1974. 
que la EMMB tal vez hubiera merecido una más generosa transmisión de facultades por parte del poder central. «Claro está -añade- que es posible que se haya preferido aguardar a que la nueva Entidad entre en funcionamiento para ver si por su dinamismo y gestión se hace acreedora a una potenciación de sus funciones» (49).

Desde las posturas oficiales es indudable la intención descentralizadora. Así, Samaranch considera que se trata de una decisión política eminentemente descentralizada, pues dice: "Prácticamente todas las funciones atribuidas al Ministerio de la Vivienda, este ir y volver de Barcelona, quedarán desconcentradas y radicadas en este Organo presidido por nuestro Gobernador civil. Pero lo importante para mí es la planificación, que para la comarca quedará en manos de la EMMB y para la Provincia en manos de la Diputación (50).

Según Masó, "efectivamente, son más las resoluciones que ahora se pueden tomar en el mundo local de las que antes era posible. Por ejemplo, antes todo tenía que ir al Ministerio de la Vivienda, $\mathrm{y}$ en este momento todo quedará en personas localizadas en Barcelona" (51).

UdINA MARTORELL ve una importante "desconcentración» en el hecho de que a través del Organo las facultades del Ministerio de la Vivienda, que antes se decidían en Madrid, pasarán a decidirse en Barcelona. Y aclara que esto es más que una delegación, por cuanto el Organo desconcentrado tendrá funciones decisorias del Ministerio de la Vivienda en la aprobación de los planes generales y planes urbanísticos en el Area y en la Provincia. Por otra parte, ninguna delegación de los Ministerios podrá tener actuaciones en el Area sin antes presentar el proyecto al Organo (52).

Abundan las críticas negativas sobre el Organo desconcentrado. PI Y SUÑER se manifiesta en los términos siguientes:

(49) Vid. J. Francesc Valus, en El Correo Catalán, Barcelona, 22 septiembre 1974. (50) Alfredo ReXACH, «Barcelona, una experiencia piloto: la Entidad Municipal Metropolitana», La Actualidad Española, Barcelona, 8 septiembre 1974.

(51) Alfredo REXACH, «Barcelona, una experiencia piloto: la Entidad Municipal Metropolitana», La Actualidad Española.

(52) Para el Círculo de Economía es positiva la pertenencia al órgano desconcentrado de los representantes a nivel provincial de los distintos Ministerios implicados en urbanismo, pero, no obstante, no se ha aprovechado la oportunidad para dar un paso hacia organizaciones más descentralizadas.

La Administración central - vía órgano desconcentrado- continúa manteniendo todas las atribuciones, incluso la facultad de aprobar Planes parciales, que antes con todas sus limitaciones competían a la Comisión Provincial de Urbanismo de la comarca, en el ámbito de sus respectivas competencias. 
«La ciudad pierde facultades, pues cuanto acuerde ha de ser aprobado definitivamente por el organismo desconcentrado que se crea en Barcelona. Basta leer el número 2 del artículo 15 del Decreto-ley para constatar que la aprobación definitiva de los planes generales y el Plan Metropolitano se acordará por el Organo creado en dicho artículo 15, el cual depende del Ministerio, formando parte del mismo, bajo la presidencia del Gobernador civil, los representantes del Ministerio de Hacienda, Gobernación, Obras Públicas, Educación y Ciencia, Industria, Comercio, Vivienda, Información y Turismo y Planificación del Desarrollo, además de un representante de la Organización Sindical y dos miembros designados por al Ministerio de la Vivienda.

Si bien con arreglo al extremo 1 del artículo 4, corresponde al Ente creado redactar los planes generales y municipales de ordenación, es lo cierto que esto es una función de propuesta, porque el acuerdo ha de ser ministerial» (53).

El señor Mas CANTI, Presidente del Círculo de Economía de Barcelona, opina que: "El Ministerio de la Vivienda y los otros Ministerios mantienen -como Entes- su última palabra a nivel de planificación, con la cual la tan famosa descentralización - de ahí la denominación de Organo desconcentrado y no descentralizadono se lleva a la práctica en este caso" (54).

Don Juan Oller Valls, Alcalde de San Adrián de Besós, ve a la Administración central con los mismos atributos que tenía antes del Decreto-ley creador de la EMMB, y agrega: "Ahora a través del Organo desconcentrado es donde se centralizan sus atribuciones en correspondencia con la Entidad. Salvando también lo que puedan decir las normas, la-Administración (que no hay que olvidar que es parte interesada, por las inversiones que realiza y recursos que aporta) mantiene principalmente una supervisión y ejerce una función de tutela en materia urbanística» (55).

Don José JANÉ Solá, catedrático de Política Económica de la Universidad de Barcelona, cree que "hasta hoy la centralización se ha realizado desde y en Madrid, y con el Organo desconcentrado se va a centralizar in situ. El problema no es, pues, de desconcentra-

(53) Vid. «Opiniones sobre la nueva Entidad Municipal Metropolitana», La Vanguardia Española, 5 septiembre.

(54) Vid. «Opiniones para un organismon, Diario de Cataluña, Barcelona, 18 septiembre 1974.

(55) Vid. "Opiniones para un organismo», Diario de Cataluña, Barcelona, 18 septiembre 1974. 
ción, sino de descentralización. $\mathrm{Y}$ este problema sigue vigente después del Decreto-ley de 24 de agosto de este año, ni más ni menos que como estaba antes» (56).

Para Carreras SerRa, Vicepresidente del Banco Industrial del Mediterráneo, la desconcentración de funciones, al contrario de la descentralización, supone una mayor atribución de competencias a la Administración central, en detrimento de la Administración local. Las facultades de aprobación atribuidas a la Comisión de Urbanismo de Barcelona -Administración local- han pasado a ser competencia del Organo desconcentrado -Administración central- . Por tanto, no es una cuestión opinable, sino cierta, que la Administración del Estado se ha visto reforzada con la aparición del Decreto (57).

El Director de la Comisión Gestora del Area Metropolitana, señor BRUNA DE QUIXANo, adoptando una postura un tanto ecléctica, opina que «más que un reforzamiento de la Administración central, el Organo desconcentrado ha sido una manifestación de la voluntad de que sea in situ que se aprueben los planes urbanísticos que afectan a la Provincia de Barcelona.

Será muy interesante contemplar la filosofía de las normas de constitución y funcionamiento del nuevo Organo, que será una nueva Comisión de Urbanismo, pero con funciones más amplias que las que tenía la que ahora se extingue.

Según el Decreto-ley, sus componentes no tienen por qué ser, en su mayoría, funcionarios de la Administración central, sino representantes de los distintos Ministerios que se citan. Bueno sería que cada Departamento designara como representante suyo en el Organo a personalidades ilustres barcelonesas, que sin duda podrían conocer los problemas y necesidades urbanísticas de la Provincia con mayor profundidad.

Si en la composición del nuevo Organo desconcentrado se incluyen personalidades barcelonesas conocedoras de nuestra problemática urbanística, ello sería un paso hacia la descentralización» (58).

Don Antonio de Moragas, decano del Colegio de Arquitectos,

(56) Vid. «Opiniones para un organismo», Diario de Cataluña, Barcelona, 18 septiembre 1974.

(57) Vid. "Opiniones para un organismo», Diario de Cataluña, Barcelona, 18 septiembre 1974.

(58) Vid. «Opiniones para un organismo», Diario de Cataluña, Barcelona, 18 septiembre 1974. 
dice: «No comprendo cómo el organismo denominado desconcentrado pueda presentarse como un intento de descentralización, cuando en realidad será peor que una centralización, pues será una centralización in situ. Basta leer quiénes formarán dicho cuerpo. Esencialmente estará formado por los representantes en la Provincia de los distintos Departamentos ministeriales, ninguno elegido por los habitates de la misma» (59).

Para el Presidente de "Amics de la Ciutat», señor PoAL, «la idea de descentralizar, o sea, que en una primera impresión parece que no dependemos de la Administración central, pero al crear el Organo desconcentrado, uno se da cuenta que la EMMB no puede dar aprobación definitiva a sus planes si no la da este Organo descontrado, compuesto sólo de representantes de la Administración central. En otras palabras, situaciones que hasta ahora el Alcalde podría resolver por sí, en la actualidad, al incorporarse Barcelona a la EMMB, estará sujeto al Organo desconcentrado" (60).

Una de las más extensas críticas es la de Trfas FARGAS (61), para quien los cambios han de llegar por las vías de la descentralización y democratización de la gestión del Estado.

Al referirse al argumento técnico con que tradicionalmente se ha defendido la descentralización, dice que un Estado industrial moderno es algo tan complejo de administrar que no es posible hacerlo eficazmente de forma centralizada. Por ejemplo: el reconocimiento de los problemas de Barcelona por parte de los barceloneses, que los sufren cada día, les hace más eficientes a la hora de resolverlos, de lo que puedan ser los funcionarios en Madrid, que, por un lado, no tienen una experiencia del tema que tan directamente les afecte, y por otro, han de repartir su atención entre mil cuestiones de carácter nacional. Luego la eficacia aconseja descentralizar, dándole al "nativo" poder para actuar en las cuestiones que a él sólo atañen.

Razona el argumento político diciendo que «el ciudadano medio entiende mejor los problemas locales (camas hospitalarias disponibles en su ciudad, por ejemplo), o por lo menos, y en general, le interesan más que las grandes cuestiones nacionales (política monetaria, relaciones diplomáticas con Rusia, pongo por caso). Por

(59) Vid. La Actualidad Española, Barcelona, 7 septiembre 1974.

(60) Vid. Laura Palmes, aLa Entidad Municipal Metropolitana a debate. Problemática y crítica de su estructura», El Correo Catalán, 8 septiembre 1974.

(61) Ramón Trfas Fargas, «Otra ocasión perdida: la Entidad Municipal Metropolitana», El Correo Catalán, Barcelona, 24 septiembre 1974. 
ello el mecanismo ingreso-gasto público municipal suele apreciarlo mejor». Por este motivo la participación en el proceso político a nivel local suele obtener la colaboración desinteresada del público, siempre que éste pueda tomar parte directa y eficaz en el mismo.

Por eso se dice que la descentralización favorece la democratización del país en general, razón de peso para los demócratas.

O sea, que la democratización pasa hoy por la descentralización, que se puede llamar simplemente descentralización o autonomía o federalismo.

Todavía cita un argumento nuevo que se esgrime con insistencia en los Estados Unidos de Norteamérica a raíz del escándalo Watergate: se ha demostrado una vez más que el poder corrompe y que el poder absoluto corrompe absolutamente (lord AcTON).

Bien sabido es que las relaciones intergubernamentales con la metrópoli pueden aspirar a servir diversos valores: libertad, participación y eficacia.

En cuanto al valor de la libertad, cabe preguntarse si la existencia de múltiples unidades de gobierno constituye una barrera a la arbitrariedad, o si la complejidad gubernamental proporciona una cortina de humo tras la cual ciertos intereses pueden manipular en su beneficio el proceso de la toma de decisiones.

Es indudable que el Municipio como "organismo intermediario» es una barrera clave al uso arbitrario del poder. Así lo veía MonTESQUIEU en defensa de este valor de libertad, entendido como libertad negativa - libertarse de algo-, en este caso del posible mando arbitrario, pues dondequiera que hay un gobierno monolítico no se debe subestimar la continuada vitalidad de la idea de que el Gobierno local sirve al valor de la libertad, generalmente comprendido como libertad contra la opresión.

En cuanto al valor de participación, si el hombre es un animal social, debe participar en las asambleas de ciudadanos (de las que dijo Tocoueville que son a la libertad lo que las escuelas primarias son a la ciencia), pues si bien un reducido número de notables determina la política pública local, la idea de que el gobierno local es particularmente conducente al valor de participación, sigue siendo un reverenciado canon de teoría política. A medida que el nivel de gobierno se acerca más al individuo, el Municipio le ofrece inigualables oportunidades de acceso y participación en el proceso del gobierno.

En cuanto al valor de eficacia, escribe Mill: «Es tan grande y 
variado el conjunto de deberes públicos... que, aunque sólo sea por el principio de división de trabajo, es indispensable repartirlo entre las autoridades centrales y locales». "Aunque las autoridades locales y el público sean inferiores a las centrales en el conocimiento de los principios de la Administración, tienen la compensadora ventaja de un interés mucho más directo en el resultado. Es únicamente el público local el que llama la atención del Gobierno hacia los puntos en que pueden requerir corrección.

La principal ocupación de la autoridad central debiera ser la de dar instrucción, y la de la autoridad local el aplicarla. El poder debe estar localizado, y el saber debe estar centralizado.

El gobierno local, pues, es conducente a los valores de la libertad, participación y eficacia.

La eficacia puede lograrse asignando cada servicio público a un nivel gubernamental cuya jurisdicción territorial sea exactamente igual al área del servicio público o al área sobre la que dicho servicio ha de tener difusión».

Para Madison (62) los mismos valores engendrados por el gobierno local - libertad, participación, eficacia- adquieren un significado vacío si estos gobiernos no son más que bastiones al servicio de intereses especiales. Y esto porque, según él, el hombre no es sólo animal social, sino animal faccioso, que está siempre creando facciones, movido por el celo religioso, por ambiciones políticas o económicas, por aspiraciones sociales, etc. Ante el temor de la corrupción de estas facciones, MADISON intenta decir adiós a las "asambleas de ciudadanos", con lo que podremos afirmar que en teoría es un poderoso argumento para la centralización o al menos para gobiernos locales de gran envergadura, como éste de la EMMB, que nos ha servido para este comentario.

En cuanto a los Vocales del Organo desconcentrado, Trías FarGAS dice: "Serán en general unos funcionarios anodinos de los distintos Ministerios, verdaderas aves de paso por estas tierras, que uno no imagina enfrentándose con sus Departamentos en defensa de los intereses de Barcelona. $O$ pueden concebiblemente ser personas de aquí que nombrarán los distintos Ministerios directamente y que deberán seguir, lógicamente, las instrucciones de sus mandantes. No sé cuál fórmula me parece menos acertada. A la desesperada, seguramente me inclinaría por esta última. En cambio, bri-

(62) Madison fue Presidente de los Estados Unidos de Norteamérica y autor de un libro, titulado El federalista, que defendía la recién nacida Constitución. 
llan conspicuamente por su ausencia en este supremo Organo desconcentrado, por lo menos de derecho propio, los representantes de nuestras instituciones locales y los miembros (excepto el Gerente funcionario) de los órganos rectorales del Ente, o sea, de su Consejo y de su Comisión Administrativa. ¡Me imagino los conflictos entre unos y otros! Desgraciadamente, pues, de descentralización tampoco nada. (Ya lo dice el Decreto: "desconcentración" y no más)».

Según Broggi Trfas, la creación de la EMMB no supone ninguna solución para la conurbación barcelonesa. Después de asegurar que Cataluña tiene porcentajes de empleo cada vez más elevados en relación al total nacional y que al mismo tiempo el empleo allí tiende a concentrarse en el Area Metropolitana de Barcelona, cree lógico pensar que Madrid no va a consentir un organismo que controle y abarque el conjunto del Area, aunque sólo tenga atribuciones administrativas y planificadoras. De hecho un tal organismo administrativo, con el poder económico que representa, tendría un peso muy importante dentro de la vida política del país. Y según él todavia no está permitido un centro de poder que no emane directamente del centro neurálgico del sistema político (63).

\section{CRITICAS SOBRE LA EMMB}

Las críticas que se vienen formulando a la EMMB son numerosas y heterogéneas, oscilando sus matices desde el optimismo moderado al más abierto pesimismo.

Entre las críticas optimistas podemos citar la del Alcalde de San Adrián de Besós, para quien "la EMMB puede ser, por vía de compenetración entre Barcelona y su comarca, el organismo idóneo para afrontar unos problemas que les son comunes".

Para JANÉ SolÁ, «la nueva situación permite, por lo menos, algo tan importante como es la coordinación e incluso la auténtica explotación común de tantos y tantos servicios públicos cuyo caos administrativo está actuando a modo de verdadero cuello de botella para el desarrollo de toda la zona; lo mismo puede decirse de las necesarias infraestructuras, pues quizá ahora se tenga un

(63) Albert Broggr Trias, aTemas de economía regional. La nueva Entidad Municipal Metropolitana», La Vanguardia Española, Barcelona, 3 octubre 1974. 
poco más de fuerza a la hora de obtenerlas de los Ministerios correspondientes".

En opinión del Marqués de CASTELl-Florite, el instrumento que se crea es amplio $y$, aunque imperfecto, válido. "Un organismo regional con mucha responsabilidad y jurisdicción. La simple lectura del artículo 15 descubre la intención de crear un pequeño gobierno administrativo regional de primer grado. En él incidirán los programas de los distintos Departamentos ministeriales afectados en el área, evitando interferencias de intereses parciales".

$Y$ añade: "Se ha creado un marco que a mi juicio ofrece amplios matices operativos. Admitido que la Administración central no puede estar ausente a la hora de decidir cuestiones que en parte ofrecen perspectivas extralocales, habrá que establecer un diálogo democrático y constructivo con la Vida local» (64).

Se ha escrito también que Barcelona tiene, en esa experiencia, la posibilidad de gran parte de su futuro. De ahi que todo lo que haga para garantizar el buen funcionamiento del Consejo Municipal de la EMMB contribuirá al porvenir de la urbe mediterránea $\mathrm{y}$, con ella, del mismo equilibrio regional, ya que sigue siendo "cap i casal de Catalunya».

UdiNA MARTORELL adopta una postura ecléctica al criticar a la EMMB, a la que califica como políticamente decepcionante, pero no así técnicamente. Dice que: "Hay como una vuelta al Estatuto Municipal de Calvo Sotelo, en el sentido del ejercicio de las funciones por el Ayuntamiento y sus agrupaciones o mancomunidades".

Tras afirmar que el problema de las áreas metropolitanas se pretende solucionar bien nacionalizando la gestión municipal, confiándola a Organos dependientes de la Administración central, bien municipalizando, encomendando la gestión a una Entidad municipal, agrupación o mancomunidad, añade que la EMMB no será un organismo híbrido, sino intermunicipal. Se ha resuelto la municipalización de la Entidad estatal que era la Comisión de Urbanismo.

Entrena Cuesta ve con pesimismo el futuro de la nueva Entidad en el caso de falta de dinamismo, pues entonces las perspectivas serán muy negras no sólo para el territorio que abarca, sino para toda la región catalana. En definitiva, el aparato organizativo es importante, pero lo es mucho más el talante que adopten quienes habrán de hacerlo funcionar.

(64) Vid. La Vanguardia Española, Barcelona, 11 septiembre 1974. 
Con un sentido demasiado drástico, Carreras Serra se atreve a señalar como mejor solución que se suspenda la aplicación del Decreto-ley y que se prepare uno nuevo, basado en las propuestas de las Corporaciones y Entidades de Barcelona y en los estudios realizados sobre la evolución socio-económica del Area Metropolitana (65).

Si estimamos el aspecto parcial a que las críticas se refieren pudiéramos hacer tres grupos: las que consideran insuficiente la extensión territorial de la EMMB; las que hacen énfasis en su falta de medios de financiación, y las que se refieren al Organo desconcentrado, a las que anteriormente nos hemos referido.

El Círculo de Economía ha informado extensamente sobre la EMMB en el sentido de que la misma no responde a las necesidades objetivas de Barcelona y su área de influencia y no atiende a las opiniones generalizadas que el tema ha suscitado.

En el informe se destaca que el Decreto se halla en abierta contradicción con el avance del Plan Director del Area Metropolitana de Barcelona y que puede aplazar o comprometer definitivamente la revisión del mismo.

\section{INSUFICIENTE EXTENSION TERRITORIAL}

El mismo Maso ha admitido que la Entidad, al limitarse a los 28 Municipios que ahora abarca el Plan Comarcal, resulta demasiado reducida, pero ya sabemos que es ampliable.

También el Marqués de CASTELl-Florite opina que debe corregirse el ámbito territorial previsto, que estima claramente desfasado del momento actual. Destaca que el concepto comarcal, tan afectivo para todos, no es, sin embargo, en términos de urbanismo, tan aprovechable como parece (en una visión amplia y tecnológica). Ello aparte de que los límites de la "comarca 1953» ya se concibieron con poca amplitud (66).

Udina Martorell, tras lamentarse de que los límites de la recién creada Entidad no se hayan extendido más (son los mismos

(65) «Entidad Municipal Metropolitana: Perspectivas poco optimistas», Diario de Barcelona, 18 septiembre 1974.

(66) Vid. La Actualidad Española, Barcelona, 7 septiembre 1974, y La Vanguardia Española, Barcelona, 11 septiembre 1974. 
que los del Plan Comarcal del 5.3), argumenta que «tal como está previsto, el Gobierno puede añadir a la Entidad otros Municipios y comarcas. Estoy convencido que es de tal razón ampliarla que no tardaremos en ver incorporadas el Maresme, el Vallés Oriental y Occidental y la zona de Martorell»(67).

Para EnTRena Cuesta la necesidad de actualizar la regulación de los organismos rectores del Area había sido proclamada de forma reiterada, pensando no sólo en la comarca barcelonesa (donde en definitiva, bien que mal, ya venía actuando la Comisión de Urbanismo, en la cual los Municipios afectados tenían su representación), sino en una zona mucho más amplia que está requerida de planeamiento unitario y de una organización también unitaria, o cuando menos fuertemente coordinada. Desde esta perspectiva, la nueva Entidad se nos antoja notoriamente insuficiente. Unicamente deberá ser enjuiciada de forma positiva si se le considera como una cabeza de puente para la futura creación de la planificación y del aparato organizativo a que se refiere. En este sentido, interesa resaltar que los autores del Decreto-ley demuestran tener conciencia del problema, aunque, acaso por razones de prudencia, no hayan querido afrontarlo ya en este momento, puesto que, por una parte, prevén la posibilidad de una incorporación a la Entidad de otros Municipios o comarcas, y por otra, apuntaría a la aplicación de sus normas a otras comarcas de la Provincia de Barcelona (68).

Para MAS CanTi la impresión es pesimista. "Con un área territ . il tan reducida como la contemplada por la Entidad - dice-, no se puede planificar el crecimiento futuro, sino tan sólo poner parches al crecimiento pasado».

"Lo idóneo hubiera sido tener presente que el territorio a planificar hoy abarca los 167 Municipios del Area, cuya necesidad hace diez años se puso ya de manifiesto, no los 28 de la EMMB", y añade:

"La verdad es que no se han tenido en cuenta los efectos de los últimos veinte años sobre el crecimiento de Barcelona»(69).

Según BROGGI TRIAS, «una planificación satisfactoria del actual crecimiento de Barcelona y su comarca, dado el proceso de descentralización industrial y residencial fuera de sus propios límites, implicaría tener en cuenta no sólo Barcelona comarca, sino tam-

(67) Vid. El Correo Catalán, 11 octubre 1974.

(68) Vid. El Correo Catalán, Barcelona, 22 septiembre 1974.

(69) Vid. Diario de Cataluña, Barcelona, 18 septiembre 1974. 
bién todo el ámbito que cae dentro de su influencia directa. Esto es precisamente lo que había convenido en llamarse Area Metropolitana de Barcelona, que constituye el núcleo netamente definido de una unidad económica más amplia, que es la región catalana (70).

El mencionado Informe del Círculo Catalán se manifiesta con respecto al ámbito de la EMMB en los siguientes términos:

Desde 1953 a 1974 se crea un hecho urbano cada vez menos delimitable por las estructuras territoriales convencionales: es lo que se configura como Area Metropolitana de Barcelona. Dicha realidad viene integrada por nueve comarcas y 162 Municipios.

Curiosamente, el ámbito definido por la comarca, en su actual delimitación, es la porción del Area Metropolitana de mayor concentración demográfica e industrial, y hoy prácticamente saturada. El margen de maniobra urbanístico en esta zona de hecho se limita, y hay que reconocer que no es poco, a la coordinación y prestación de servicios colectivos, pero imposibilita ya toda planificación ur. banística a largo plazo, uno de cuyos instrumentos más eficaces es la reserva de suelo.

Todos los trabajos efectuados desde 1964 señalan el ámbito del Area Metropolitana de Barcelona como territorio mínimo necesario para programar el futuro urbanístico de la conurbación barcelonesa.

Fuentes Lojo opina que limitar la Entidad a Barcelona y los términos municipales que se mencionan, y que coinciden con la territorialidad que alcanzaba la competencia de la Comisión de Urbanismo y Servicios Comunes, que también desaparece, parece una falta de visión de la panorámica que el planteamiento urbanístico exige, máxime en una Provincia como la de Barcelona, por no decir una región como la catalana, y los servicios de interés metropolitano que se mencionan en el artículo 10 del referido Decreto-ley.

De todas formas, es de esperar que este fallo sea subsanado, haciendo uso de lo dispuesto en el artículo segundo, que autoriza al Gobierno a modificar dicho ámbito territorial (71).

TRÍAS FARGaS estima entre los principales defectos de la EMMB la insuficiencia de su ámbito de jurisdicción (72).

(70) Albert Broggi Trias, aLa nueva Entidad Municipal Metropolitana», La Vanguardia Española, Barcelona, 3 octubre 1974.

(71) FUENTES Lojo, artículo citado.

(72) Trias Fargas, "Otra ocasión perdidan, El Correo Catalán, 24 septiembre 1974. 
Ros Hombravella, profesor de Política Económica de la Universidad Autónoma, cree que «contener el Area Metropolitana puede resultar perjudicial. Pero saltando esto, todo depende de lo que quiera y pueda hacer el conjunto de Diputaciones de las cuatro Provincias: en este sentido, habrán de esperar el Proyecto de Ley de Régimen local y la aplicación efectiva de un sistema fiscal nuevo" (73).

Mundo Diario se ha referido a la Entidad en una serie de artículos, concluyendo que la misma no responde a las necesidades de su población, entre otras razones, porque el territorio que abarca es inferior al deseable (74).

No es, pues, raro oír llamar en los medios técnicos a la EMMB, «miniárea».

En una de las cenas-coloquio celebradas con ocasión de la V Semana Económica Internacional, el Alcalde honorario de Barcelona, don José María de Porcioles, dijo que Barcelona padece un exiguo término municipal, inferior al de Madrid. Incluso hoy Barcelona por su comarca es todavía inferior al término municipal de la capital de España. Por eso, cuando en 1967 los técnicos de la Comisión de Urbanismo preparaban la revisión del Plan Comarcal se dieron cuenta de que con la comarca no había nada que hacer ya. Nació entonces el Area Metropolitana como necesidad para la planificación urbanística, aunque no pudo tener una traducción jurídica que le permitiera capacidad para obrar, pero nos encontramos ahora -añadió - con que esa Area Metropolitana tan mimada la perdemos y nos tenemos que limitar a la comarca.

Para Vidal Villa "la EMMB no es un acierto, y no lo es por la sencilla razón de que no respeta los pilares básicos sobre los cuales debe asentarse cualquier intento de planificación urbana: primero el abarcar todo el territorio que realmente posee la urbe a planificar (los Municipios de la comarca de Barcelona como el centro de una vasta región que se extiende desde el Vendrell hasta Blanes, alcanzando Martorell, Tarrasa, Sabadell, etc.), y segundo porque no se trata de un Organo realmente descentralizado, ligado a las fuerzas e intereses en presencia en Cataluña, sino ampliamente mediatizado por la Administración central. Mientras no se consiga algún tipo de autonomía regional, es difícil que los "entes", apa-

(73) Vid. La Actualidad Española, Barcelona, 7 septiembre 1974.

(74) Vid. Mundo Diario, 18 septiembre 1974. 
rentemente descentralizados, cumplan con eficacia su misión. Pero hay más; a mi entender, la EMMB es un contrasentido que se enfrenta al propio desarrollo del "capitalismo monopolista a nivel urbano", que es la tendencia hoy día predominante en la ciudad. Las grandes operaciones urbanas, frente de actividad para numerosos sectores de la industria y los servicios, tienen que orientarse sobre grandes espacios. No puede concebirse un plan coherente, incluso desde el punto de vista capitalista, sin una verdadera incidencia sobre el conjunto de la realidad urbana que se trata de ordenar» (75).

\section{FALTA DE MEDIOS DE FINANCIACIÓN}

Para Udina Martorell los recursos ordinarios reconocidos a favor de la EMMB son insuficientes, como lo son para Madrid los de la COPLACO (76).

Trfas VARGas ha escrito: «En el único momento que se deja al ente libre para que campe por sus respetos es a la hora de buscar dinero. Entre otras cosas, tiene plena libertad para pedir donativos a los buenos catalanes, o para pedir ("mendigar" creo que lo ha llamado estos días en Salou un conocido ex Alcalde) subvenciones más o menos condicionadas al poder central. En algunos casos podrá el ente solicitar que se aumente la presión fiscal de los residentes en la zona. Por parte del Estado, nada especial. Sin embargo, en estos momentos se estima en todo el mundo que por ser las grandes ciudades industriales el motor del desarrollo de las naciones y generar a la vez su principal coste social, el Estado debe asistir (véase la propuesta del profesor W. Heller) en grandes cantidades y sin condiciones a las necesidades y calidad de vida de estos núcleos tan imprescindibles para generar recaudación fiscal y progreso económico y a la vez tan capaces en la creación de costes sociales enormes. Si además recordamos que la zona suministra al fisco español una cifra anual neta (o sea, por encima de lo que directa

(75) Vid. Triunfo, 10 octubre 1974. Vidal VILLA, De la crisis mundial a don Fabián Estape, por M. Vázquez Montalbán.

VIDAL VILlA, profesor de la Universidad de Barcelona, explicó durante dos años Economía Regional en la Universidad de La Habana. Autor de Iniciación a la Eco. nomia marxista (Laia) y Economía Mundial (Salvat). Nació en México, hijo de padres españoles.

(76) Vid. El Noticiero Universal, Barcelona, 9 septiembre 1974. 
0 indirectamente gasta en ella el Estado) de unos 50.000 millones de pesetas, la parte financiera del Decreto que crea la EMMB resulta claramente mezquina e insolidaria» (77).

El pronóstico sobre las posibilidades de actuación de la nueva Entidad, según BRUNA DE QUIXANO, tampoco es muy feliz al nacer con muy escasos recursos económicos. Hubiera sido muy deseable el contar con una fuerte asignación con cargo a los Presupuestos Generales del Estado, dado el fuerte déficit de descapitalización que sufre todo el territorio de la influencia de Barcelona.

También Oller Valls, Alcalde de San Adrián de Besós, opina en este sentido que "las consecuencias en cuanto a ordenación del territorio me parece serán positivas,-siempre y cuando la Entidad disponga de los recursos económicos y ayudas precisas y de buenos administradores para llevar adelante sus fines»(78).

\section{OTRAS CRITICAS}

Otros autores han criticado a la EMMB porque supone una merma del poder decisorio en materia de planificación. Otros hacen referencia a diversos aspectos, como la carencia de «gestación democrática".

Al preguntarle al Ministro de la Gobernación qué opinaba de las citadas críticas, dijo, entre otras cosas, que "las críticas siempre sirven para orientarse, ya que repreșentan diversos puntos de vista, aunque en este caso concreto algunas han estado desenfocadas. Sin embargo, las hemos seguido con interés, y teniendo presente todo lo que se ha dicho, hemos tratado de reforzar aquellos aspectos que doctrinalmente eran más importantesn. Y añadió que "desde la perspectiva del Gobierno nos parece bien que exista un estado de opinión que se interese por el tema; lo peor hubiera sido que un asunto de tanta importancia hubiera caído en el vacío» (79).

(77) Ramón TRfas Fargas, «Otra ocasión perdida: la Entidad Municipal Metropolitana», El Correo Catalán, Barcelona, 24 septiembre 1974.

(78) Diario de Cataluña, 18 septiembre 1974.

(79) Vid. La Vanguardia Española, Barcelona, 26 noviembre 1974. 


\section{CONCLUSION}

Si pensamos que este nuevo ente territorial constituye una experiencia piloto y que va a operarse sobre un volumen demográfico y económico que en proyección directa o indirecta puede representar una sexta o séptima parte de España, si tenemos en cuenta además que las enseñanzas que de este ensayo trascendente se deriven son susceptibles de ser aplicadas en otras Provincias españolas, no es de extrañar la expectación que ha suscitado su aparición dentro y fuera de Cataluña. 